Household Search and the Aggregate Labor Market

Jochen Mankart, Rigas Oikonmou

December 2012 Discussion Paper no. 2012-25 


$\begin{array}{ll}\text { Editor: } & \text { Martina Flockerzi } \\ & \text { University of St. Gallen } \\ & \text { School of Economics and Political Science } \\ & \text { Department of Economics } \\ & \text { Varnbüelstrasse 19 } \\ & \text { CH-9000 St. Gallen } \\ & \text { Phone +41 71 224 23 25 } \\ & \text { Fax } \quad+41712243135 \\ & \text { Email seps@unisg.ch } \\ & \text { School of Economics and Political Science } \\ & \text { Department of Economics } \\ & \text { University of St. Gallen } \\ & \text { Varnbüelstrasse 19 } \\ \text { Publisher: } & \text { CH-9000 St. Gallen } \\ & \text { Phone +41 71 224 23 25 } \\ & \text { Fax +41 71 224 31 35 } \\ & \text { http://www.seps.unisg.ch }\end{array}$




\title{
Household Search and the Aggregate Labor Market ${ }^{1}$
}

\author{
Jochen Mankart, Rigas Oikonomou
}

Author's address:

Jochen Mankart

Institute of Economics (FGN-HSG)

Varnbüelstrasse 19

$\mathrm{CH}-9000$ St. Gallen

Phone +41712242155

Fax $\quad+41712242874$

Email_jochen.mankart@unisg.ch

Website www.mankart.net

Rigas Oikonomou

HEC Montréal

2953, chemin de la Côte-Sainte-Cathrine 91

Montréal

Canada H3T $1 \mathrm{C} 3$

Phone +514340 6445

Website https://sites.google.com/site/rigasoikonomou/home

\footnotetext{
${ }^{1}$ We are indebted to Albert Marcet, Chris Pissarides, and especially Rachel Ngai for their continuous support and guidance.

We also benefited a lot from the comments of Francesco Caselli, Alex Michaelides, Andreas Müller participants at the LSE Macro Workshop, the XV workshop on Dynamic Macroeconomics in Vigo, the German Economic Association meeting in Kiel, the European Workshop in Macroeconomics in Munich, and also participants in seminars at the HEC Montreal, the Humboldt University Berlin, the London School of Economics, Sciences Po, St. Gallen University, the University of Cambridge, and the University of Cyprus. We are grateful to Athan Zafirov for excellent research assistance.
} 


\begin{abstract}
Sharing risks is one of the essential economic roles of families. The importance of this role increases in the amount of uncertainty that households face in the labor market and in the degree of incompleteness of financial markets. We develop a theory of joint household search in frictional labor markets under incomplete financial markets. Households can insure themselves by savings and by timing their labor market participation. We show that this theory can match one aspect of the US data that conventional search models, which do not incorporate joint household search, cannot match. In the data, aggregate employment is pro-cyclical and unemployment counter-cyclical, but their sum, the labor force, is acyclical. In our model, and in the US data, when a family member loses his job in a recession, the other family member joins the labor force to provide insurance.
\end{abstract}

\title{
Keywords
}

Heterogeneous Agents, Family Self Insurance, Labor Market Search, Aggregate Fluctuations

JEL Classification

E24, E25, E32, J10, J64 


\section{Introduction}

Economic decisions, such as whether or not to work and whether or not to search for job opportunities in the labor market, are made jointly in the family. When financial markets are incomplete, as they are in the real world, these decisions are influenced by the incentive of households to insure against shocks to their labor income. Unemployment is such a shock and families are an important insurance device against it. To understand this point, consider the following realistic example: assume that a household has one of its members employed and the other member is out of the labor force (OLF, hereafter). This is a pattern of intra-household specialization that we observe frequently in the data. Usually the primary earners in US households are husbands, and the secondary earners are wives. Assume also that the economy is in a recession, when the separation rate is high and the job finding rate is low. If the husband loses his job in a recession, the household income suffers a big shock. Moreover, if financial markets are incomplete, income losses have an impact on consumption. But joint search can provide an important buffer against these risks. The wife can join the labor force, and actively search in the market, to maximize the chances that the household will have at least one of its members employed next period.

In this paper, we present a theoretical framework that puts joint search at the heart of a search model. We consider an economy where each household is a couple, whose members search for job opportunities in a labor market that is subject to frictions. We show that when financial markets are incomplete, and therefore unemployment is a risk for the household, its members will arrange their labor market behavior so as to provide insurance against this risk. We illustrate that our model can match one aspect of the US data, that conventional search models, which do not assign an important role to family insurance as we do, cannot match: in the data, aggregate employment is very procyclical and unemployment countercyclical, but their sum, the labor force, is nearly acyclical. Our theory can match this aspect of the data by virtue of the fact that unemployment in the family is a bigger risk in recessions than it is in booms, and because household members search together to overcome this risk.

In Section 2 of our paper we show that these adjustments of search and labor supply at the household level are a feature of the US data. We show that secondary household earners (wives in our sample) time their flows in and out of the labor market to provide insurance and that in the event of the family's primary earner's experiencing a spell of unemployment, there is an "added worker effect" that induces the wife to join the labor force. We investigate, using data from the Current Population Survey (CPS, hereafter), the adjustment of the labor supply, arguing that the added worker effect increases the probability of entering the labor force both instantaneously, in the month where the unemployment shock occurs, but also for months after the spell. We also document a sizable response at the intensive margin by showing that wives increase their search intensity, i.e., the number of alternative methods used to look for jobs, in response to spousal unemployment.

In Section 3 we present the model. We construct a general equilibrium model with search frictions in the labor market as well as shocks in individual (idiosyncratic) labor productivity. There are incomplete financial markets as in Krusell and Smith (1998). Families can self-insure against shocks to their labor income by building a stock of precautionary savings, but, in our model, they can also insure against unemployment through joint search in the labor market. Household members are ex ante identical, but through realized differences in idiosyncratic productivity each household has a "primary" 
and a "secondary" earner. To put it differently, though our theory does not assign a particular gender to either household member, it endogenizes primary and secondary earners in the family on the basis of labor income potential. The model gives rise to differences in labor income within the household because idiosyncratic productivity is not perfectly correlated between its members. These differences then make families want to place their most productive member in the labor market and their least productive one OLF. The simplification of assuming that individuals in the economy are ex ante identical also serves to keep the model close to the previous literature with incomplete financial markets but with bachelor households. We add to this considerable literature by presenting a framework with dual earners.

In Section 4 we show that the model can match the pattern of the intrahousehold specialization, in terms of the three states of employment, unemployment, and OLF. That is to say, it can match the fraction of US households that have both of their members employed, the fraction of households that have one individual employed and the other one OLF, and so on. We also illustrate that the model can match the size of the added worker effect as we document it in our empirical analysis, as well as the flows across labor market states. By matching the cross sectional labor market evidence, we demonstrate that even though our theory is a simplification of reality, it is a very good framework for understanding the behavior of the marginal household and its secondary earner.

Our main results are presented in Section 5. We show that our model produces a very procyclical employment and countercyclical unemployment, but a correlation of labor force participation with aggregate output that matches its empirical counterpart in the US data. We also illustrate that the success of the model is due to families' responding to higher unemployment risks in recessions with joint search in the labor market. When we remove family self-insurance from the economy, considering a version of the model where each individual is single, as is the case in standard models, the labor force becomes very procyclical, in contrast to the US data.

This paper is related to several strands in the literature: First, a central motivation of our work is to present a model with realistic frictions in the labor market that can match the cyclical properties of labor force participation. In a small related literature this has proved to be a difficult task. For example, Tripier (2004), using a search and matching model as in Merz (1995); and Veracierto (2008), using a version of the equilibrium unemployment theory of Lucas and Prescott (1974), both get a labor force participation that is highly correlated with economic activity. The intuition is straightforward: when wages are high or jobs are easier to find in expansions, the payoffs to labor market search are higher and therefore individuals join the labor force in expansions. In contrast, in our framework with incomplete markets, individuals want to flow into the labor force in recessions in order to ward off the higher risk of unemployment. This family self-insurance effect offsets the effect from the standard intertemporal substitution channel.

Second, there is only a handful of papers in the vast literature of search theoretic models of the labor market that consider three labor market states - employment, unemployment, and OLF. For the most part, the literature has restricted attention to models that feature only employment and unemployment. One recent exception is the work of Krusell et al. (2011, 2012), who consider an incomplete financial market model with search frictions and endogenous labor force participation decisions. Their work is an important step towards building a theoretical framework that can explain patterns of worker reallocation over all labor market states. In fact, in the US data there are more individuals each month that flow from the labor force to OLF than individuals that flow between employment and 
unemployment, and therefore it is obvious that search models should explain these flows. Unlike Krusell et al. (2011, 2012), who consider a bachelor household economy, we model households as couples. Our theory therefore attributes a substantial part of the flows in and out of the labor force to the effort on the part of families to deal with unemployment risks.

As mentioned previously, within the context of the literature of models of heterogeneous agents and wealth accumulation (see Krusell and Smith (1998), Chang and Kim (2006, 2007) among others), the idea that families are an insurance device against labor market risks is not common. A few recent exceptions are the following: Chang and Kim (2006) develop a framework where households consist of two members, a male and a female, and use it to investigate how individual labor supply rules affect the value of the aggregate elasticity of labor supply. Attanasio et al. (2005) quantify the welfare benefits from female labor force participation when income uncertainty increases in a model with incomplete asset markets. Attanasio et al. (2008) and Heathcote et al. (2010) analyze the effects of changes in the economic environment, such as changes in gender wage premia or changes in idiosyncratic labor income risks, on the historical trends of female labor supply. The difference from our work is that we emphasize the role of families in circumventing frictions in the labor market, while these papers overlook the importance of frictions. Guler et al. (2012) explore the implications of joint search on optimal reservation wage policies. They use a stylized McCall search model to highlight the fact that joint search gives an opportunity to families for climbing up the wage ladder. We build a general equilibrium framework with realistic heterogeneity that views joint search as an insurance device against unemployment.

\section{The US Labor Market}

\subsection{Cyclical Behavior of the Labor Market}

Aggregate labor market statistics. Table 1 summarizes the US labor market business cycle statistics. The data are constructed from the Current Population Survey (CPS) and span the years 1994 to 2011. The unemployment rate (U) is highly counter-cyclical and nine times as volatile as aggregate output. Aggregate employment (E) has more than two-thirds of the volatility of output at business cycle frequencies and is very procyclical. The labor force (LF), however, is not volatile and its contemporaneous correlation with the GDP is low.

Figure 1 shows the business cycle component of the labor market aggregates (left axis, blue lines) along with detrended output (right axis, red line). The shaded regions denote NBER recessions (two consecutive quarters of negative GDP growth). The top left panel shows the behavior of unemployment relative to output. The top right plots aggregate employment and the bottom left labor force participation. Labor force participation in the US economy clearly contains a component that is not correlated with economic activity as measured by the GDP. There are several periods in the data where the LF moves oppositely to the GDP but also periods where the two aggregates move together. For example, according to our measure of the business cycle component of the time series, the LF dropped initially during the most recent downturn but then, after January 2009, aggregate output recovered: yet the labor force did not. 
Table 1: US Business Cycle: Labor Market Statistics

\begin{tabular}{lcccc}
\hline & $\mathrm{E}$ & $\mathrm{U}$ & $\mathrm{LF}$ & $\mathrm{LF}+\mathrm{NS}$ \\
\hline$\frac{\sigma_{x}}{\sigma_{y}}$ & 0.77 & 9.01 & 0.27 & 0.21 \\
$\rho_{x, y}$ & 0.82 & -0.90 & 0.33 & 0.10 \\
\hline
\end{tabular}

This table is based on data from the CPS for the years 1994 to 2011 and refers to individuals aged 16 and older. The data are logged and HP filtered and all quantities refer to quarterly aggregates and are expressed relative to a detrended measure of the GDP. $\frac{\sigma_{x}}{\sigma_{y}}$ is the volatility of $x$ relative to the volatility of the GDP. $\rho_{x, y}$ is the correlation of $x$ with the GDP. $E$ is the employment to population ratio, $U$ refers to the unemployment rate (number of unemployed agents over the labor force), and $L F$ is the labor force (number of workers who are either employed or unemployed) over the total population. $L F+N S$ is constructed by adding non-active job seekers to labor force participants. See Appendix 7.1 for a detailed descripton of the data.

The bottom right panel of Figure 1 shows an alternative measure of LF participation. In addition to employed and unemployed individuals, it also includes individuals who are OLF but want to find work, and would be available to take up potential job offers. These individuals are non-searchers (NS in our notation), meaning that even though they would accept job offers, they do not actively look for jobs in the labor market. Because they do not search, they are considered in the official US statistics as OLF. By adding the population of non-searchers to the population of unemployed job seekers and employed individuals, we wish to illustrate that the non cyclicality of labor force participation in the US data is not due to the precise definition of the labor force used by the CPS. If individuals moved from not wanting jobs to wanting jobs but not searching in economic expansions, then the measure LF+NS that is plotted in the Figure would be procyclical. According to the data, this is not the case. Instead the data suggests that individuals join the pool of non-searchers in recessions. The contemporaneous correlation of the non-searcher population with GDP (not shown in the Table) is -0.67 . The correlation between LF+NS and the GDP is 0.10 (the last column in Table 1). ${ }^{1}$

Aggregate labor market for demographic groups. Table 2 documents the cyclical behavior of employment, unemployment, and labor force participation for various demographic groups. Panels $\mathrm{A}$ and $\mathrm{B}$ show the statistics for married men and women who are at least 16 years of age. Panels $\mathrm{C}$ and $\mathrm{D}$ show the analogous statistics for single (not married) individuals. There are several noteworthy features. First, note that the labor force participation of married individuals is less procyclical than the labor force participation of singles. The contemporaneous correlation with the GDP is 0.07 for married men and -0.22 for married women, while it is 0.58 for single men and 0.38 for single women.

\footnotetext{
${ }^{1}$ Shimer (2004) documents that the search intensity as measured by the CPS (the number of search methods used by individuals to find jobs) is also not procyclical. In fact he documents that in the 2001 recession there was a rise in search intensity in the CPS sample. This finding fits very well in our analysis since those individuals that search actively for jobs are counted as unemployed by the CPS survey. If search intensity is not procyclical, labor force participation is also not procyclical. We refer the reader to that paper for details.
} 

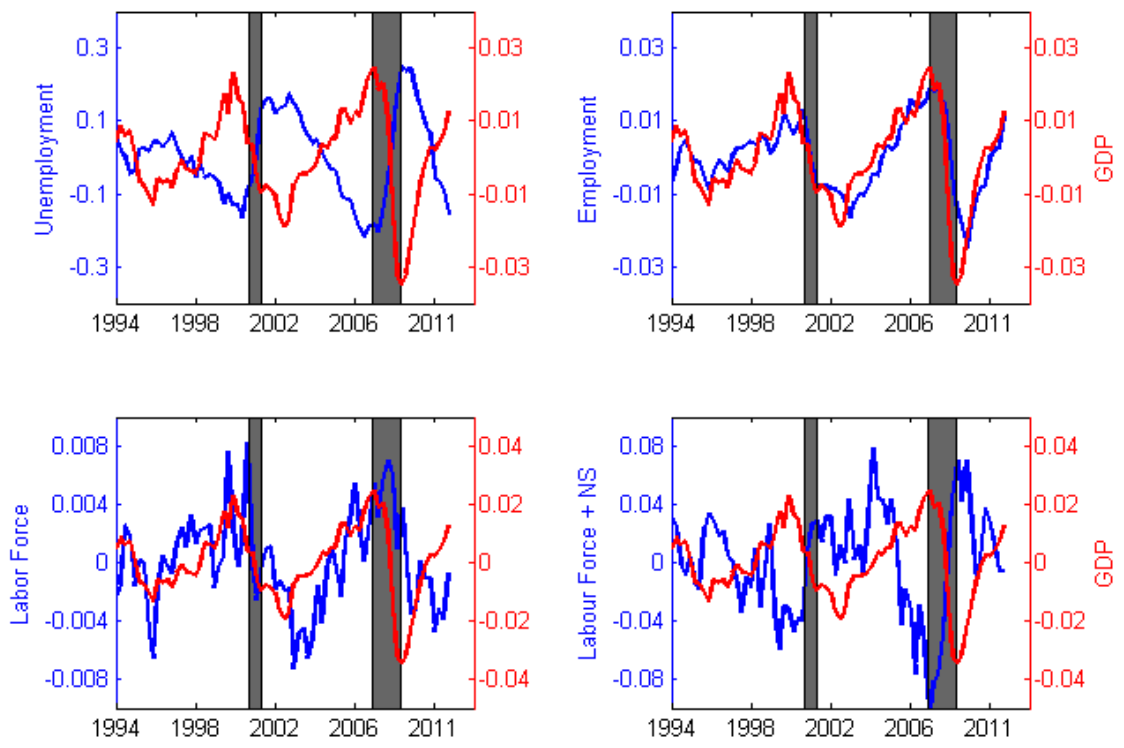

Figure 1: Cyclical Component of Labor Market Statistics

This figure shows the business cycle component of aggregate employment, unemployment rate and LF participation (two alternative definitions). Shaded areas denote NBER recessions. The right axis in each plot represents detrended output.

It seems that within a married household, the male spouse has the traditional role of the breadwinner: he stays in the labor force independently of the phase of the cycle. The family chooses to allocate him to work or to search for jobs even in recessions when job opportunities are scarce. The female spouse is the pivotal household member that moves in and out of the labor force more readily because the family assigns to her the role of the secondary earner. In particular, as shown in Panel B of Table 2, she joins the labor force in recessions despite the fact that job finding rates are lower then. This timing reflects the incentive to provide insurance against unemployment shocks hitting the male spouse. For single individuals, on the other hand, there are presumably less family insurance concerns and hence searching for job opportunities in the labor market becomes considerably more procyclical.

This last point has to be taken with caution, though. Joint labor market decisions do not necessarily concern only husbands and wives, but also other members of a family. Each member that contributes to the family's resources should to some extent time their labor market participation to minimize the impact of unemployment on the household. By this metric even single (non-married) individuals in the data are not single in the strict sense of economic models; they may well be part of a broader family in which case the timing of the labor force participation for these groups should also, perhaps to a lesser extent, reflect household insurance concerns. We return to this issue in the next section.

\subsection{Labor Market Flows}

Table 3 documents the monthly transitions of the US workforce across labor market states: employment, unemployment, and OLF. Panel A reports the average transition probabilities 
Table 2: US Business Cycle: Labor Market Statistics by Gender and Marital Status

\begin{tabular}{|c|c|c|c|c|c|c|c|c|}
\hline & \multicolumn{4}{|c|}{ A: Married men } & \multicolumn{4}{|c|}{ C: Single men } \\
\hline & $\mathrm{E}$ & $\mathrm{U}$ & $\mathrm{LF}$ & $\mathrm{LF}+\mathrm{NS}$ & $\mathrm{E}$ & $\mathrm{U}$ & $\mathrm{LF}$ & $\mathrm{LF}+\mathrm{NS}$ \\
\hline$\frac{\sigma_{x}}{\sigma_{y}}$ & 0.64 & 13.4 & 0.24 & 0.22 & 1.45 & 8.75 & 0.49 & 0.39 \\
\hline \multirow[t]{3}{*}{$\rho_{x, y}$} & 0.78 & -0.90 & 0.07 & -0.09 & 0.86 & -0.90 & 0.58 & 0.40 \\
\hline & \multicolumn{4}{|c|}{ B: Married women } & \multicolumn{4}{|c|}{ D: Single women } \\
\hline & $\mathrm{E}$ & $\mathrm{U}$ & $\mathrm{LF}$ & $\mathrm{LF}+\mathrm{NS}$ & $\mathrm{E}$ & $\mathrm{U}$ & $\mathrm{LF}$ & $\mathrm{LF}+\mathrm{NS}$ \\
\hline$\frac{\sigma_{x}}{\sigma_{y}}$ & 0.52 & 9.36 & 0.40 & 0.39 & 0.96 & 7.11 & 0.50 & 0.45 \\
\hline$\rho_{x, y}$ & 0.43 & -0.85 & -0.22 & -0.35 & 0.73 & -0.83 & 0.38 & 0.30 \\
\hline
\end{tabular}

$\frac{\sigma_{x}}{\sigma_{y}}$ is the volatility of $x$ relative to the volatility of the GDP. $\rho_{x, y}$ is the correlation of $x$ with the GDP. See Table 1 for variable definitions and a detailed description of the data.

for the population in the years 1994-2011. Each month, about 7\% of OLF individuals join the labor force, and $2.3 \%$ of employed workers become OLF. ${ }^{2}$ Moreover, $23.5 \%$ of the unemployed drop out of the labor force each month. Thus, over our sample period, there are more workers flowing from employment to OLF than to unemployment, and more workers moving from OLF to employment each month than from unemployment to employment.

Panels B and C show the same flows separately for males and females. Each month $8.2 \%$ of the men and $6.3 \%$ of the women join the labor force, and $3.3 \%$ of employed men and $4.3 \%$ of employed women drop out of the labor force. There are slight differences in the size of the flow rates, as men are more attached to the labor force than are women. Overall, the labor force participation rates are about $70 \%$ for men and $50 \%$ for women.

Accounting for inactivity and worker flows in and out of the LF. Table 4 shows LF participation patterns in more detail. We are interested in describing which

\footnotetext{
${ }^{2}$ Note that $4.5 \%$ of OLF individuals move directly to employment in the following month. There are two relevant possibilities: the first is that this is an immediate consequence of time aggregation since monthly horizons are more than enough for a worker to make a transition between inactivity and employment without having a recorded unemployment spell. The second pertains to the search behavior of non-searchers. For this group, the work of Jones and Riddell $(1998,1999)$ has demonstrated that they have transition probabilities into employment that are nearly half as large as those of unemployed workers. We have verified that this is indeed the case in our CPS sample. Non-searchers move to employment in any given month with a probability of $14.3 \%$ and to unemployment at a rate of $17.8 \%$, meaning that there is considerable mobility between these states. However, even if we were to consider only individuals that do not want jobs as OLF, there still are sizable flows. Each month, 2.27\% of employed individuals and $13 \%$ of unemployed individuals join the pool of individuals that are not looking and do not want jobs and $6.8 \%$ of OLF who do not want jobs become either employed $(3.8 \%$ ) or unemployed (either active or passive searchers) each period. See also Krusell et al. (2011) for an analysis of the transition probabilities with the CPS data. Moreover, Nagypál (2005) shows that around 40\% of the transitions from employment to OLF result in a flow directly to employment in the next month. Some of these workers have searched for a new job while employed, obtained a job offer but the starting date of the new job is in the next month.
} 
Table 3: Monthly Flows: Total and by Gender

\begin{tabular}{|c|c|c|c|c|c|c|c|c|c|}
\hline \multirow{3}{*}{ From } & \multicolumn{3}{|c|}{ A: Total } & \multicolumn{3}{|c|}{ B: Men } & \multicolumn{3}{|c|}{ C:Women } \\
\hline & \multicolumn{3}{|c|}{ To } & \multicolumn{3}{|c|}{ To } & \multicolumn{3}{|c|}{ To } \\
\hline & $\mathrm{E}$ & $\mathrm{U}$ & OLF & $\mathrm{E}$ & $\mathrm{U}$ & OLF & $\mathrm{E}$ & $\mathrm{U}$ & OLF \\
\hline $\mathrm{E}$ & 0.964 & 0.013 & 0.023 & 0.967 & 0.015 & 0.018 & 0.960 & 0.012 & 0.029 \\
\hline $\mathrm{U}$ & 0.258 & 0.506 & 0.235 & 0.279 & 0.525 & 0.203 & 0.241 & 0.483 & 0.274 \\
\hline OLF & 0.045 & 0.025 & 0.929 & 0.052 & 0.031 & 0.948 & 0.042 & 0.022 & 0.936 \\
\hline
\end{tabular}

This table shows the monthly flow rates from one labor market state to another one. The states are: employed, unemployed, and out of the labor force. See Table 1 for variable definitions and a detailed description of the data.

individuals are typically OLF, and which groups account for the bulk of the flows in our sample from OLF into the LF and vice versa. Columns 1 and 2 show the composition of inactivity (viz., OLF): for all individuals aged 16 and above (first column), retired individuals represent a fraction of roughly $46 \%$; married women account for $32 \%$ (and $18.5 \%$ if they are not retired), and married men account for 19\% (5\% if not retired). Individuals who are unmarried (including retired widowers and young individuals in school or college) constitute $49.23 \%$ of the inactive population. Furthermore, as shown in the last two rows of the Table, disabled and ill individuals (independently of marital status) account for $13.5 \%$ of the total and non-searchers account for roughly $7 \% .^{3}$

In column 2 we look at individuals aged 25-55. In this age group, married women account for the largest share of OLF individuals: $48.5 \%$ if they are not in retirement. Married men who are not retired constitute $9.7 \%$ of this sub-sample, and unmaried individuals, 37\%. Disabled individuals account for $25.7 \%$ and non-searchers for $11.2 \%$. In columns 3 and 4 of Table 4 we look at the demographic groups that account for the bulk of the flows from OLF into the LF (column 3) and from the LF to OLF (column 4). We focus on individuals aged between 25 and 55. Married women are the most important constituent in both of these flows, with $41 \%$ and $44 \%$ if not retired. ${ }^{4}$ Unmarried individuals also account for a large part, $39 \%$ and $42 \%$, respectively. Other groups (married men, disabled, and non-searchers) are relatively modest shares of the total. ${ }^{5}$

According to the results in Table 4, there are two groups that can be considered as marginal workers in the US economy, meaning individuals that flow readily in and out of

\footnotetext{
${ }^{3}$ We do not model disability shocks explicitly as do Gallipoli and Turner (2008), but we can at least partially capture the effects of disability through an idiosyncratic labor productivity process (see Section 3). The basic idea is that disability reduces the productivity and the potential labor income of the individual, which induces a withdrawal from the LF.

${ }^{4}$ Not retired in the case of these flows means that an individual was not retired prior to flowing into the LF, and also that she did not quit the LF to become retired.

${ }^{5}$ We think that it is interesting to look into the reasons that married women and unmarried individuals become OLF. Our analysis reveals the following: whereas typically unmarried individuals are OLF either because disabled or because not searching, married women flow to OLF, according to the CPS classification, for "family and other reasons" or to become non-searchers. For instance, in terms of the flow rate from the LF to OLF for unmarried individuals, flows to disability or illness are $16 \%$ and flows to non-searching are $31 \%$. For married women, $59 \%$ are flows to OLF for "family or other" reasons, and also a considerable proportion $(22 \%)$ become non-searchers.
} 
Table 4: Accounting for OLF Individuals

\begin{tabular}{lccccc}
\hline & \multicolumn{2}{c}{ OLF groups } & & \multicolumn{2}{c}{ Worker Flows } \\
\cline { 2 - 3 } \cline { 6 - 6 } Age & $\geq 16$ & $25-55$ & & OLF $\rightarrow$ LF & LF $\rightarrow$ OLF \\
Retired & 0.459 & 0.065 & & 0.026 & $25-55$ \\
Married Men & 0.190 & 0.116 & & 0.164 & 0.153 \\
Married Men (non-retired) & 0.048 & 0.097 & & 0.138 & 0.085 \\
Married Women & 0.317 & 0.513 & & 0.420 & 0.451 \\
Married Women (non-retired) & 0.133 & 0.486 & & 0.408 & 0.439 \\
Non-Married & 0.498 & 0.371 & & 0.387 & 0.424 \\
Disabled or Ill & 0.135 & 0.257 & & 0.033 & 0.054 \\
Non-Searchers & 0.070 & 0.112 & & 0.062 & 0.059 \\
\hline
\end{tabular}

Columns 1 and 2 decompose the OLF population into various demographic groups. Column 1 corresponds to the civilian population of more than 16 years of age. Column 2 corresponds to individuals aged 25 to 55 . Columns 3 and 4 decompose the flows from OLF to LF and from LF to OLF by demographic group. See Table 1 for variable definitions and a detailed description of the data.

the LF and form the largest fractions of inactive workers: married women and unmarried individuals (whether male or female). Our theory which considers households as having more than one individual would therefore miss an important aspect if singles in the data are singles in the sense of economic models. We said previously that this is not the case. First, because an unmarried individual to which we refer here as a single is not necessarily living on their own. In order to quantify this point, we computed the percentage of OLF individuals that live together with someone who is in the LF. We found this to be $84 \%$ of the agegroup 25-55. Second, though obviously a portion of the US population do live on their own, they nevertheless may be part of families. For example students attending college are clearly dependent on their parents and at the same time they are living away from home.

In essence, our theory is one that views being out of the labor force as a state that presupposes the presence of a main earner in the family. Given these considerations, our theory is a good approximation to the US data. However, if we were to be explicit about who the primary and who the secondary earners are, then we would have to introduce a considerable degree of heterogeneity in our economy in order to match the data in all relevant dimensions. For instance, we would have to include households with more than two individuals, which would add a huge computational burden. We would obviously encounter similar difficulties with the data if we wanted to characterize the joint labor supply decisions in households with many members. For this reason, in the next section, where we investigate the added worker effect, we follow the previous literature and consider the response of the labor force participation of the wife to the husband's unemployment spells. 


\subsection{Added Worker Effects}

This section provides evidence for joint search in US households. We use data from the CPS on married couples to estimate the impact of a husband's unemployment spell on the wife's search and LF participation. Our data covers the years 1994-2011 and refers to families where both the husband and the wife are aged between 25 and 55 . For each household, the husband is employed at the start of the month and either employed or unemployed in the next month. ${ }^{6}$

Columns 1 and 2 of Table 5 show the impact of an unemployment spell suffered by the male spouse on the likelihood that the wife joins the LF. Column 1 shows that this probability increases by 8 percentage points. This represents an increase of roughly $67 \%$ in this probability. The effect is measured by the coefficient on $E U_{m}$ (male spouse makes an employment to unemployment transition). Column 2 decomposes an unemployment spell into three sources. The variable "Loss" represents unemployment spells that are due to a job loss, the variable "Quit" represents spells where the individual has quit his job, and the variable "Layoff" represents spells in which his work is suspended for a given period but he expects a call back from his previous employer. The results suggest that losses lead to a rise in the probability of 10.8 percentage points (which nearly doubles the likelihood that that the wife joins the LF), quits to a rise of 9.4 percentage points (an increase of $78 \%$ ) and layoffs to a rise 1.5 points relative to a couple where the husband remains employed in both months.

These numbers may seem surprising, especially if one thinks of quits as being initiated on the worker's side. Workers that quit must, all else being equal, be better placed to deal with the separation than workers that get fired. One possible explanation for why quits and losses lead to similar increases in the wife's probability of joining the LF, is that on many occasions job losses are accompanied by insurance payments by either the government or the firm. For instance, in the US, workers that are eligible for unemployment insurance are job losers and not job quitters. Similarly, severance payments in principle are given after a termination that is initiated by the firm. To the extent that these payments mitigate the effect of a job loss on the household's budget, they will also mitigate the added worker effect. ${ }^{7}$ Another explanation is that job terminations, no matter where they originate, derive from the same principle: that the surplus of the match is negative and that the productivity of the worker is higher elsewhere. ${ }^{8}$ On this interpretation, it is not surprising that quits and losses lead to similar increases in the transition probability. Layoffs on the other hand lead to a considerably smaller increase, because a layoff is a temporary termination of the match and therefore does not represent a big shock to the family's

\footnotetext{
${ }^{6}$ We have dropped observations where the husband flows from employment to OLF. As Nagypál (2005) explains, typically prime aged workers that drop from employment directly to OLF frequently have another job lined up. In this case, a transition to non-employment is not really the kind of shock to the household resources that we would expect to induce an AWE. In our sample, for instance, $0.65 \%$ of all employed husbands flow out of the labor force directly from employment, and $49.7 \%$ of these transitions are reversed in the following month with a flow directly to employment. Moreover, roughly one-sixth of all male flows from E to OLF are a result of illness or disability. We anticipate that in response to a disability shock the AWE will be considerably smaller if the wife has to care for her ill husband (see Gallipoli and Turner (2009)). Nevertheless, given the small number of observations of E to OLF male flows, we have found that our estimates were unaffected no matter whether we dropped these observations or not.

${ }^{7}$ See for example Engen and Gruber (2001) who document the impact of unemployment insurance on the AWE.

${ }^{8}$ See for example Borjas and Rosen (1980).
} 
resources. $^{9}$

In columns 3 and 4 we estimate the effect of the husband's unemployment on the wife's search intensity. Our dependent variable is the number of different search methods that a wife uses to look for jobs (such as sending out resumes, reading newspaper ads, etc.) and it takes the value zero if she doesn't search, one if she employs one method, two if two methods are used, etc. In the CPS dataset, there are 12 alternative methods recorded. Individuals that don't search (use zero methods) are considered as being OLF, but also some workers that look for jobs but the methods that they use are not considered as "Active Search" by the CPS, are excluded from the LF.

In column 3 we show that the number of methods increases by 0.292 when the husband experiences an employment to unemployment transition. Given the estimate of the constant in the regression this effect nearly doubles the number of methods used. In column 4 we show that the number of methods increases by 0.418 for job losers and by 0.424 for quits. Again in this case "Layoffs" have a smaller impact on the behavioral response of female labor market search. Documenting this effect is important for two reasons. First, because insofar as family insurance is concerned, increasing the number of search methods is a response at the intensive margin by the same token that joining the labor force can be thought of as an extensive margin response. Second, because, as discussed earlier, the CPS considers as OLF those non-employed individuals that either do not search or search too little, and therefore an increase in search methods entails, for some individuals, a transition from OLF into the LF and is thus relevant to us.

Shimer (2004) documents that aggregate search intensity in the US is not procyclical. However, models based on search theory predict that it is. Typically, in the theoretical models, individuals are more eager to look for jobs at times when the payoffs to search are higher (e.g., in expansions). Therefore, it is important to show that the husband's unemployment risk has an impact on the search intensity margin even though this is not the main focus of our paper.

Dynamic response. Looking at the instantaneous response of female LF participation might be flawed for two reasons. First, because the change in the desired labor supply occurs when the relevant information of an imminent unemployment spell arrives; and second, because families may be slow to react to the change in the labor market status of their primary earner. Consider a couple where the husband knows with certainty that his job will end in one or two months because he is given advance notice of his termination. In that case, joint search may be optimal even before the unemployment spell occurs. Similarly, the response could be delayed if there are adjustment costs, for example for families with children, or if the couple fails to realize the magnitude of the shock to its labor income: in the latter case, the husband searches for a new job in the first month and only if his search is unsuccessful might joint search then be optimal.

Table 6 documents the dynamic responses of female labor force participation to spousal

\footnotetext{
${ }^{9}$ We are not the first to document these facts. Lundberg (1985) for example, uses monthly employment histories from a sample of the Seattle and Denver Income Maintenance Experiments (SIME DIME) to conclude that if a husband is unemployed then the probability that his wife enters the labor force increases by $25 \%$, and the probability of her leaving the labor force is $33 \%$ lower. She is also $28 \%$ less likely to leave employment for unemployment (see also Spletzer (1997)).
} 
Table 5: Estimation of the Added Worker Effect

\begin{tabular}{|c|c|c|c|c|}
\hline & \multicolumn{2}{|c|}{ Labor Force Participation } & \multicolumn{2}{|c|}{ Search Intensity } \\
\hline & 1 & 2 & 3 & 4 \\
\hline $\mathrm{EU}_{m}$ & $\begin{array}{l}0.0800^{* * *} \\
(0.00294)\end{array}$ & & $\begin{array}{l}0.2920^{* * *} \\
(0.00562)\end{array}$ & \\
\hline $\operatorname{Loss}_{m}$ & & $\begin{array}{c}0.1086^{* * *} \\
(0.00441)\end{array}$ & & $\begin{array}{c}0.4185^{* * *} \\
(0.00844)\end{array}$ \\
\hline Layoff $_{m}$ & & $\begin{array}{c}0.0153^{* * *} \\
(0.00471)\end{array}$ & & $\begin{array}{c}0.1015 \\
(0.0090)\end{array}$ \\
\hline Quit $_{m}$ & & $\begin{array}{c}0.0943^{* * *} \\
(0.00967)\end{array}$ & & $\begin{array}{c}0.4247^{* * *} \\
(0.01874)\end{array}$ \\
\hline No. of Kids & $\begin{array}{c}-0.0130 * * * \\
(0.0009)\end{array}$ & $\begin{array}{c}-0.0130^{* * *} \\
(0.0009)\end{array}$ & $\begin{array}{c}-0.1090^{* * *} \\
(0.00184)\end{array}$ & $\begin{array}{c}-0.1090^{* * *} \\
(0.00184)\end{array}$ \\
\hline No. of Kids $\leq 5$ & $\begin{array}{c}-0.0613^{* * *} \\
(0.00167)\end{array}$ & $\begin{array}{c}-0.0613^{* * *} \\
(0.00167)\end{array}$ & $\begin{array}{c}-0.1329^{* * *} \\
(0.00352)\end{array}$ & $\begin{array}{c}-0.1331^{* * *} \\
(0.00352)\end{array}$ \\
\hline Black $_{f}$ & $\begin{array}{l}0.0570^{* * *} \\
(0.00182)\end{array}$ & $\begin{array}{c}0.0571^{* * *} \\
(0.00182)\end{array}$ & $\begin{array}{l}0.1773^{* * *} \\
(0.00365)\end{array}$ & $\begin{array}{l}0.1775^{* * *} \\
(0.00365)\end{array}$ \\
\hline White $_{f}$ & $\begin{array}{c}0.0074^{* * *} \\
(0.0011)\end{array}$ & $\begin{array}{c}0.0073^{* * *} \\
(0.0011)\end{array}$ & $\begin{array}{c}-0.0110^{* * *} \\
(0.00229)\end{array}$ & $\begin{array}{c}-0.0106^{* * *} \\
(0.00229)\end{array}$ \\
\hline Educ. $f$ & $\begin{array}{l}.0770^{* * *} \\
(0.0040)\end{array}$ & $\begin{array}{c}0.0773^{* * *} \\
(0.0040)\end{array}$ & $\begin{array}{c}0.2077^{* * *} \\
(0.00834)\end{array}$ & $\begin{array}{c}0.2067^{* * * *} \\
(0.00834)\end{array}$ \\
\hline Educ. $m$ & $\begin{array}{l}-0.0097^{* *} \\
(0.00401)\end{array}$ & $\begin{array}{l}-0.0105^{* * *} \\
(0.00401)\end{array}$ & $\begin{array}{l}-0.0033 \\
(0.00828)\end{array}$ & $\begin{array}{l}-0.0016 \\
(0.00829)\end{array}$ \\
\hline $\operatorname{Age}_{f}$ & $\begin{array}{l}0.0084^{* * *} \\
(0.00321)\end{array}$ & $\begin{array}{l}0.0087^{* * *} \\
(0.00321)\end{array}$ & $\begin{array}{l}0.0379^{* * *} \\
(0.00664)\end{array}$ & $\begin{array}{l}0.0371^{* * *} \\
(0.00664)\end{array}$ \\
\hline $\operatorname{Age}_{f}^{2}$ & $\begin{array}{c}-0.0002^{* * *} \\
(0.00008)\end{array}$ & $\begin{array}{c}-0.0003^{* * *} \\
(0.00008)\end{array}$ & $\begin{array}{c}-0.0008^{* * *} \\
(0.00017)\end{array}$ & $\begin{array}{c}-0.0008^{* * *} \\
(0.00017)\end{array}$ \\
\hline $\operatorname{Age}_{f}^{3}$ & $\begin{array}{c}1.99 \mathrm{e}-06^{* * *} \\
(7.09 \mathrm{e}-07)\end{array}$ & $\begin{array}{c}2.03 \mathrm{e}-06^{* * *} \\
(7.09 \mathrm{e}-07)\end{array}$ & $\begin{array}{c}5.81 \mathrm{e}-06^{* * *} \\
(1.46 \mathrm{e}-06)\end{array}$ & $\begin{array}{c}5.64 \mathrm{e}-06^{* * *} \\
(1.46 \mathrm{e}-06)\end{array}$ \\
\hline $\operatorname{Age}_{m}$ & $\begin{array}{c}-0.0174^{* * *} \\
(0.0034)\end{array}$ & $\begin{array}{c}-0.0175^{* * *} \\
(0.0034)\end{array}$ & $\begin{array}{c}-0.0516^{* * *} \\
(0.00701)\end{array}$ & $\begin{array}{c}-0.0518^{* * *} \\
(0.00701)\end{array}$ \\
\hline $\mathrm{Age}_{m}^{2}$ & $\begin{array}{c}0.0004^{* * *} \\
(0.00009)\end{array}$ & $\begin{array}{c}0.0004^{* * *} \\
(0.00009)\end{array}$ & $\begin{array}{c}0.0012^{* * *} \\
(0.00018)\end{array}$ & $\begin{array}{c}0.0013^{* * *} \\
(0.00018)\end{array}$ \\
\hline $\mathrm{Age}_{m}{ }^{3}$ & $\begin{array}{c}-3.13 \mathrm{e}-06^{* * *} \\
(7.04 \mathrm{e}-07)\end{array}$ & $\begin{array}{c}-3.14 \mathrm{e}-06^{* * *} \\
(7.04 \mathrm{e}-07)\end{array}$ & $\begin{array}{c}-0.00001^{* * *} \\
(1.45 \mathrm{e}-06)\end{array}$ & $\begin{array}{c}-0.00001^{* * * *} \\
(1.45 \mathrm{e}-06)\end{array}$ \\
\hline $\mathrm{R}^{2}$ & 0.0104 & 0.0104 & 0.025 & 0.025 \\
\hline Observations & &, 505 & &, 498 \\
\hline
\end{tabular}

Regression 1 shows the percentage point increase in the probability that a wife joins the labor force if her husband has made a transition from employment to unemployment in a given month. Regression 2 gives detailed results distinguishing between the different reasons for unemployment (e.g., job losses, quits, and layoffs). In regressions 3 and 4 the dependent variable is the search intensity (number of search methods used). The data are from the CPS 1994-2011. [***] indicates significance at or below 1 percent, $\left[{ }^{* *}\right]$ at or below 5 percent, and $\left[{ }^{*}\right]$ at or below 10 percent. 
unemployment. We estimate the following equation with dynamic panel data:

$$
\begin{aligned}
\text { Transition }_{i, t} & =\sum_{\tau=-2}^{\tau=+2} \alpha_{\tau} I(\text { Husband Spell in } t+\tau)+ \\
& +Z_{t, i} \delta+\text { Time Dummies }+\epsilon_{i, t},
\end{aligned}
$$

where $Z$ is a matrix of demographic characteristics which includes, as before, the age, education, and race of both spouses, and the number of children in the household, and where $\epsilon_{i, t}$ is the error term. For the sake of brevity, we suppress the vector $\delta$ of coefficients of demographic variables from the table.

In Appendix 7.2, we explain in detail the construction of the sample used in estimating equation 1 . The basic idea is that the $\alpha_{\tau}$ coefficients capture the conditional probability that a wife that has not joined the LF $\tau-1$ periods after the husband's unemployment spell, will join in period $t+\tau$. Because the CPS tracks individuals for four consecutive months, the survey is interrupted for eight months and then another four monthly observations are collected, we can only generate data for transitions ranging from $\tau=-2$ up to $\tau=+2$. We only consider consecutive observations to avoid having to deal with censoring issues. Moreover, since in our panel for many households we only have one data point (we drop the household after a transition into the labor force is made) we did not include a household fixed effect in our estimation.

According to the results shown in the first column of Table 6 there is an AWE that increases the probability of joining the LF one and two months after the unemployment spell. There is also a mild effect on joining the LF a month before the spell, but no significant effect two months prior to the spell. The contemporaneous effect is 0.078 , leading to an increase of more than $60 \%$ in this probability. The coefficient $\alpha_{1}$ (one month after) is 0.0466, and the analogous value for $\alpha_{2}$ is 0.0339. Table 6 gives the coefficients from the entire sample, whereby unemployment is the result of any type of separation (loss, quit, or layoff). The disaggregated regression results are shown in the Appendix in Tables 14 and 15. The implications are similar to those of the static model. A job loss results in the largest behavioral response of the female labor supply, both before and after the spell, and a (temporary) layoff leads to the smallest response.

Column 2 shows the estimated coefficients of the dynamic response of the search intensity variable to the husband's unemployment spell. Our results suggest that there is a considerable rise in the number of search methods used by female spouses in this case. The contemporaneous effect is a rise in search methods by 0.259 . One (two) month(s) before the rise, it is roughly $0.11(0.10)$. The largest effect is for two months after the spell, an increase in search intensity by roughly 0.3 methods. Therefore, when the unemployment shock occurs in the family, there is a considerable and persistent response at this margin. 
Table 6: Dynamic Added Worker Effect in the Data

\begin{tabular}{lcc}
\hline & LF Participation & Search Intensity \\
\hline$\alpha_{-2}$ & 0.0096 & $0.0994^{* * *}$ \\
& $(0.0086)$ & $(0.01799)$ \\
$\alpha_{-1}$ & $0.02157^{* * *}$ & $0.1119^{* * *}$ \\
& $(0.00607)$ & $(0.01272)$ \\
$\alpha_{-0}$ & $0.0784^{* * *}$ & $0.2590^{* * *}$ \\
& $(0.00496)$ & $(0.01001)$ \\
$\alpha_{+1}$ & $.0466^{* * *}$ & $0.2264^{* * *}$ \\
& $(0.00608)$ & $(0.01233)$ \\
$\alpha_{+2}$ & $0.0339^{* * *}$ & $0.2920^{* * *}$ \\
& $(0.0084)$ & $(0.01689)$ \\
+ controls & $\ldots$ & $\ldots$ \\
$\mathrm{R}^{2}$ & 0.007 & 0.0184 \\
Observations & 441,785 & 484,610 \\
\hline
\end{tabular}

This table shows the response of a wife if her husband has made (will make) a transition from employment to unemployment two months ago, one month ago, this month, next month, or the month thereafter. The first regression shows the percentage point increase in the probability that a wife joins the labor force. Regression 2 has the wife's search intensity (number of search methods) as the dependent variable. The vector of demographic controls is identical to the one used in Table 5. The data are from the CPS 1994-2011. The last column shows the dynamic participation decision in the model. [***] Significant at or below 1 percent. [**] Significant at or below 5 percent. [*] Significant at or below 10 percent. 


\section{The Model}

\subsection{Preliminaries}

We consider an economy populated by a unit mass of households. Each household consists of two individuals that are identical in preferences and value the consumption of a general multipurpose good $c$, and also value leisure that we denote by $l$. Household utility is represented by $u\left(c_{1}, l_{1}\right)+u\left(c_{2}, l_{2}\right)$, where $c_{i}, l_{i} i \in\{1,2\}$ are the consumption and leisure of household member $i$. Both individuals have a discount factor that we denote by $\beta$.

At any point in time a household can be economically active or retired. We model retirement as an exogenous event. We assume that there is a probability $\phi_{1}$ each period with which both the household's members retire. In this case, the household has to wait for another shock $\phi_{2}$ in order to become active in the labor market. Retired households are considered out of the labor force in our economy. Non retired households may also have either of their members out of the labor force. But they can also have employed or unemployed individuals in the family. Non-retired, non-employed household members choose a level of search intensity $s_{t}$ each period. This choice variable can take on two values, $\underline{s}$ and $\bar{s}>\underline{s}$. We classify household members as either unemployed or out of labor force on the basis of $s_{t}$. Our criterion is of the following form:

$$
\text { If } s_{t}\left\{\begin{array}{l}
=\underline{s} \text { individual is OLF } \\
=\bar{s} \text { individual is } \mathrm{U}
\end{array}\right.
$$

that is, an individual is considered out of the labor force if their choice of search intensity $s_{t}$ is low. ${ }^{10}$

Job availability in the economy is limited. Given the choice $s_{t}$ there is an arrival rate of job opportunities $p\left(s_{t}, \lambda_{t}\right)<1$ for the individual. $\lambda_{t}$ denotes the total factor productivity. $p\left(s_{t}, \lambda_{t}\right)$ is increasing in both of its arguments. Therefore, a lower search intensity maps into a lower probability of finding a job next period. Higher values of the total factor productivity shift $p\left(s_{t}, \lambda_{t}\right)$ upwards, thus generating a higher arrival rate of job opportunities for non-employed individuals. ${ }^{11}$ Moreover, search in the labor market is a costly activity. To exert a level of effort $s_{t}$, the agent must spend time, looking for jobs or visiting employment sites, going through interviews, preparing and sending out resumes, etc. We assume that this cost is measured in units of foregone leisure which we denote by $\kappa\left(s_{t}\right)$.

\footnotetext{
${ }^{10}$ It simplifies the exposition considerably to cast the household's program in terms of a choice of search intensity, rather than being explicit about the labor market state (unemployment vs. OLF). Moreover, given the previous discussion, it should be clear that this classification criterion conforms with the analogous criterion used by the CPS.

${ }^{11}$ In search and matching models (see Mortensen and Pissarides (1994)) this feature would arise endogenously as a result of the firms' policies to post vacancies over the business cycle. Here we wish to avoid introducing explicitly a matching technology for two reasons. First, we are interested in understanding labor supply behavior at the household level. Therefore, modeling the demand side of the labor market is not of primary importance. Second, search and matching models have been shown to have a hard time in matching the cyclical properties of the aggregate labor market (see Shimer (2005), Mortensen and Nagypal (2007) amongst others), unless, for example, wage rigidity is introduced into the model (as in Hall (2005) and Hall and Milgrom (2008)). Solving the bargaining problem between the worker and the firm, when the worker's fallback position is determined by the family's resources and the partner's employment status, adds considerably to the computational burden, in particular because endogenizing wages is a non trivial task in such an environment.
} 
Employment is modeled as follows: Employed individuals are matched with firms in production and spend a fraction $\bar{h}$ of their unitary time endowment each period in market activities. Every match operates a technology with constant returns to scale and so without loss of generality we can aggregate and represent the total production as a final good of the form $Y_{t}=K_{t}^{\alpha}\left(L_{t} \lambda_{t}\right)^{1-\alpha} . K_{t}$ and $L_{t}$ denote the aggregate capital stock and labor input (per efficiency units) respectively. We assume that $\lambda_{t}$ evolves according to the non-stochastic transition cdf $\pi_{\lambda^{\prime} \mid \lambda}=\operatorname{Prob}\left(\lambda_{t+1}<\lambda^{\prime} \mid \lambda_{t}=\lambda\right)$.

Households face idiosyncratic labor productivity risks that we summarize in two independent stochastic processes. The first one, which we denote by $\epsilon_{i}$, is an agent specific persistent process that is independent of the agents's labor market status. For the household, we let $\epsilon$ be the vector of idiosyncratic productivities of its members. It evolves stochastically over time according to the cumulative distribution function $\pi_{\epsilon^{\prime}, \epsilon}=\operatorname{Pr}\left(\epsilon_{t+1}<\epsilon^{\prime}, \epsilon_{t}=\epsilon\right)$. The second source of uncertainty is a match quality shock: we assume that the match productivity is driven to zero at the rate $\chi\left(\lambda_{t}\right)$ each period. This effectively leads the worker and the firm to separate. The arrival of this shock is independent of the realization of $\epsilon$ and the number of employed individuals within a household but is a function of the aggregate state.

Because labor supply decisions are formulated at the extensive margin and each employed individual works $\bar{h}$ hours, existing matches maybe terminated voluntarily, that is without the arrival of the $\chi\left(\lambda_{t}\right)$ shock. Each period a household member draws a new realization of $\epsilon$ and if idiosyncratic productivity is low the individual may decide to terminate the match. Similarly, when non-employed individuals receive a job offer, they have to choose whether they want to give up the search and take up the offer, or whether to continue searching for a new job opportunity in the market. In our model therefore, flow rates from employment to non employment and vice versa are also determined endogenously through the reservation productivities and labor supply decisions at the household level.

Financial markets in the economy are incomplete and agents can self-insure by trading non-contingent claims on the aggregate capital stock subject to a borrowing limit $a_{t} \geq \underline{a} \forall t$. We assume that $\underline{a}=0$, thereby ruling out borrowing from the economy. Households earn a return $R_{t}$ each period on their savings. Wages per efficiency unit of labor $w_{t}$ and rental rates $R_{t}$ are determined in competitive markets. Aggregate capital $K_{t}$ depreciates at a rate of $\delta$ each period. Finally, we let $\Gamma_{t}$ denote the density function of agents over the relevant state space (of household employment status, productivity, and wealth). The law of motion for the distribution of workers is defined as: $\Gamma_{t+1}=\mathcal{T}\left(\Gamma_{t}, \lambda_{t}\right)$ where $\mathcal{T}$ is the relevant transition operator.

\subsection{Value Functions}

Each period $t$ (and after the resolution of all relevant uncertainty) a non-employed nonretired agent chooses optimally the number of search units $s_{t}$ to exert. This choice of $s_{t}$ leads to a probability $p\left(s_{t}, \lambda_{t}\right)$ of receiving a job offer in the next period. When this opportunity arrives, the new values of the idiosyncratic productivity $\epsilon_{t+1}$ are sampled and the aggregate state vector $\left\{\Gamma_{t+1}, \lambda_{t+1}\right\}$ is revealed, and as discussed previously, the household will decide whether it wants to keep its member searching or send her to work. Notice that central to this decision is the employment status of the other household member. Let $V^{n n}$ be the lifetime utility of a household with two non-employed individuals $V^{e n}\left(V^{n e}\right)$ be the analogous object for a household that has the first (second) member employed and $V^{e e}$ the value function when both members are employed. If the household has two non- 
employed individuals and one of them receives a job offer, the choice to be made requires the comparison of $V^{n n}$ with $V^{e n}$. In this respect, the continuation utility of the household is given by $Q^{e n}=\max \left\{V^{n n}, V^{e e}\right\}$, i.e., the upper envelope over the relevant menu of choices. Analogously, we define $Q^{n e}=\max \left\{V^{n n}, V^{n e}\right\}$ and $Q^{e e}=\max \left\{V^{n n}, V^{e n}, V^{n e}, V^{e e}\right\}$.

To illustrate the household's program, we first consider two individuals who are out of work but not retired. The household has a stock of wealth $a_{t}$ and a productivity endowment $\epsilon_{t} \cdot{ }^{12}$ It allocates resources between current consumption (for its two members) and savings and chooses the number of units of search effort. Applying standard arguments we can represent the program recursively by

$$
\begin{gathered}
V^{n n}(a, \epsilon, \Gamma, \lambda)=\max _{a^{\prime} \geq \underline{a}, s_{i}} \sum_{i} u\left(c_{i}, l_{i}\right)+\beta \phi_{1} \int_{\epsilon^{\prime}, \lambda^{\prime}} V^{R}\left(a^{\prime}, \epsilon^{\prime}, \Gamma^{\prime}, \lambda^{\prime}\right) d \pi_{\epsilon^{\prime} \mid \epsilon} d \pi_{\lambda^{\prime} \mid \lambda} \\
+\beta\left(1-\phi_{1}\right) \int_{\epsilon^{\prime}, \lambda^{\prime}}\left[p\left(s_{1}, \lambda\right)\left(1-p\left(s_{2}, \lambda\right)\right) Q^{e, n}\left(a^{\prime}, \epsilon^{\prime}, \Gamma^{\prime}, \lambda^{\prime}\right)\right. \\
\left.+p\left(s_{2}, \lambda\right)\left(1-p\left(s_{1}, \lambda\right)\right) Q^{n, e}\left(a^{\prime}, \epsilon^{\prime}, \Gamma^{\prime}, \lambda^{\prime}\right)\right)+p\left(s_{1}, \lambda\right) p\left(s_{2}, \lambda\right) Q^{e e}\left(a^{\prime}, \epsilon^{\prime}, \Gamma^{\prime}, \lambda^{\prime}\right) \\
\left.+\left(1-p\left(s_{1}, \lambda\right)\right)\left(1-p\left(s_{2}, \lambda\right)\right) V^{n n}\left(a^{\prime}, \epsilon^{\prime}, \Gamma^{\prime}, \lambda^{\prime}\right)\right] d \pi_{\epsilon^{\prime} \mid \epsilon} d \pi_{\lambda^{\prime} \mid \lambda}
\end{gathered}
$$

subject to the constraint set

$$
a^{\prime}=R_{\lambda, \Gamma} a-\sum_{i} c_{i} \quad \Gamma^{\prime}=\mathcal{T}(\Gamma, \lambda) \text { and } \quad l_{i}=1-\kappa\left(s_{i}\right)
$$

where $V^{R}$ is the lifetime utility of a retired household. Optimal choices for these agents consist of current consumption and a pair of search intensity levels. Given $s_{1}$ and $s_{2}$ (the search intensities for members 1 and 2), the household can anticipate that both of its members will receive a job offer next period with probability $p\left(s_{1}, \lambda\right) p\left(s_{2}, \lambda\right)$ (in which case the envelope $Q^{e e}$ applies) and that with probability $1-\left(1-p\left(s_{1}, \lambda\right)\right)\left(1-p\left(s_{2}, \lambda\right)\right)$ either one or both of its members will encounter a job opportunity in the market. ${ }^{13}$

In a similar fashion, we can represent the program that has its first member employed and the second non-employed.

$$
\begin{gathered}
V^{e n}(a, \epsilon, \Gamma, \lambda)=\max _{a^{\prime} \geq \underline{a}, s_{2}} \sum_{i} u\left(c_{i}, l_{i}\right)+\beta \phi_{1} \int_{\epsilon^{\prime}, \lambda^{\prime}} V^{R}\left(a^{\prime}, \epsilon^{\prime}, \Gamma^{\prime}, \lambda^{\prime}\right) d \pi_{\epsilon^{\prime} \mid \epsilon} d \pi_{\lambda^{\prime} \mid \lambda} \\
+\beta\left(1-\phi_{1}\right) \int_{\epsilon^{\prime}, \lambda^{\prime}}\left[p\left(s_{2}, \lambda\right)(1-\chi(\lambda)) Q^{e, e}\left(a^{\prime}, \epsilon^{\prime}, \Gamma^{\prime}, \lambda^{\prime}\right)\right)+p\left(s_{2}, \lambda\right) \chi(\lambda) Q^{n, e}\left(a^{\prime}, \epsilon^{\prime}, \Gamma^{\prime}, \lambda^{\prime}\right) \\
+\left(1-p\left(s_{2}, \lambda\right)\right) \chi(\lambda) V^{n n}\left(a^{\prime}, \epsilon^{\prime}, \Gamma^{\prime}, \lambda^{\prime}\right) \\
\left.+\left(1-p\left(s_{2}, \lambda\right)\right)(1-\chi(\lambda)) Q^{e n}\left(a^{\prime}, \epsilon^{\prime}, \Gamma^{\prime}, \lambda^{\prime}\right)\right] d \pi_{\epsilon^{\prime} \mid \epsilon} d \pi_{\lambda^{\prime} \mid \lambda}
\end{gathered}
$$

subject to the constraint set

$$
a^{\prime}=R_{\lambda, \Gamma} a+w \epsilon_{1}-\sum_{i} c_{i} \quad \Gamma^{\prime}=\mathcal{T}(\Gamma, \lambda) \text { and } \quad l_{1}=1-\bar{h}, \quad l_{2}=1-\kappa\left(s_{2}\right) .
$$

\footnotetext{
${ }^{12}$ We assume as in Mazzocco (2007), Cubeddu and Ríos-Rull (2003) that wealth is a commonly held resource in the household.

${ }^{13}$ Notice that the distribution $\Gamma$ becomes a state variable in the worker's value function. In order to forecast prices in the current context and to make optimal savings and labor market search decisions, a knowledge of $\Gamma^{\prime}$ is necessary since this object determines the economy's aggregate capital stock and effective labor in the next period.
} 
As discussed previously, employed individuals run the risk of losing their jobs from two sources. First a fraction $\chi\left(\lambda_{t}\right)$ of all exiting matches terminate each period due to the arrival of the match quality shock. Second, the sampling of the new value of $\epsilon$ generates the risk of separation since if $\epsilon^{\prime}$ is too low, the household may decide that it is not worthwhile to spend $\bar{h}$ of its time working. The program of a household where only the second member is employed $V^{\text {ne }}$ is defined analogously.

The program of a household with two employed members is given by

$$
\begin{gathered}
V^{e e}(a, \epsilon, \Gamma, \lambda)=\max _{a^{\prime} \geq \underline{a}} \sum_{i} u\left(c_{i}, l_{i}\right)+\beta \phi_{1} \int_{\epsilon^{\prime}, \lambda^{\prime}} V^{R}\left(a^{\prime}, \epsilon^{\prime}, \Gamma^{\prime}, \lambda^{\prime}\right) d \pi_{\epsilon^{\prime} \mid \epsilon} d \pi_{\lambda^{\prime} \mid \lambda} \\
+\beta\left(1-\phi_{1}\right) \int_{\epsilon^{\prime}, \lambda^{\prime}}\left[(1-\chi(\lambda))^{2} Q^{e e}\left(a^{\prime}, \epsilon^{\prime}, \Gamma^{\prime}, \lambda^{\prime}\right)\right. \\
+(1-\chi(\lambda)) \chi(\lambda)\left(Q^{e n}\left(a^{\prime}, \epsilon^{\prime}, \Gamma^{\prime}, \lambda^{\prime}\right)+Q^{n e}\left(a^{\prime}, \epsilon^{\prime}, \Gamma^{\prime}, \lambda^{\prime}\right)\right) \\
\left.+\chi(\lambda)^{2} V^{n n}\left(a^{\prime}, \epsilon^{\prime}, \Gamma^{\prime}, \lambda^{\prime}\right)\right] d \pi_{\epsilon^{\prime} \mid \epsilon} d \pi_{\lambda^{\prime} \mid \lambda}
\end{gathered}
$$

subject to the constraint set

$$
a^{\prime}=R_{\lambda, \Gamma} a+\sum_{i}\left(w \epsilon_{i}-c_{i}\right) \quad \Gamma^{\prime}=\mathcal{T}(\Gamma, \lambda) \text { and } \quad l_{i}=1-\bar{h} .
$$

Finally, the value function of a retired household is given by

$$
\begin{aligned}
V^{R}(a, \epsilon, \Gamma, \lambda) & =\max _{a^{\prime} \geq \underline{a}} \sum_{i} u\left(c_{i}, l_{i}\right) \\
+\beta \int_{\epsilon^{\prime}, \lambda^{\prime}}\left[\phi_{2} V^{n n}\left(a^{\prime}, \epsilon^{\prime}, \Gamma^{\prime}, \lambda^{\prime}\right)\right. & \left.\left.\left.+\left(1-\phi_{2}\right) V^{R}\left(a^{\prime}, \epsilon^{\prime}, \Gamma^{\prime}, \lambda^{\prime}\right)\right] d \pi_{\epsilon^{\prime} \mid \epsilon} d \pi_{\lambda^{\prime} \mid \lambda}\right)\right)
\end{aligned}
$$

subject to the constraint set

$$
a^{\prime}=R_{\lambda, \Gamma} a-\sum_{i} c_{i} \quad \Gamma^{\prime}=\mathcal{T}(\Gamma, \lambda) \text { and } \quad l_{i}=1 .
$$

Several comments are in order. First, note that we assume that the income for both unemployed and OLF workers is zero. This assumption is made mainly to avoid the complications of having to talk about eligibility for government insurance schemes, as it is not clear how benefits would be distributed across the population. For instance, inactive workers in principle should not receive any replacement income (workers that receive benefits are counted as unemployed and their job search effort is monitored by the employment agency) but in our model there is considerable mobility between the two non-employment states. Keeping track of benefit histories would add a considerable computational burden.

In our model, unemployment insurance would affect the households' decisions via two margins. First, it would crowd out family insurance (see Cullen and Gruber (2000)) for eligible households ${ }^{14}$. Second, it would crowd out the precautionary role of savings (see Engen and Gruber (2001)). Our theory predicts that households with fewer assets make more use of joint labor supply and joint search and, therefore, the effect from the second channel mitigates the impact from the first. This is what happens in our model and

\footnotetext{
${ }^{14}$ According to Wang and Williamson (2002) roughly $30 \%$ of unemployed individuals in the US receive unemployment compensation.
} 
in Section 4 we will show that despite the absence of benefits, it can match the AWE as we have documented it in the US data. Our model therefore does not exacerbate intrahousehold insurance.

Finally, note that retired households in the model have no income from social security. This simplifying assumption is made because retired households in the model are present only to help us match the fraction of US couples that have both of their members OLF. In the model, when a couple retires it does not affect the cyclical component of the aggregate labor force participation, employment, or unemployment, because retirement is given as an event that is independent of the cycle. Retired families can be thought of as if they drop out of the economy altogether and are replaced by new families when the shock $\phi_{2}$ is realized. But without the retirement state, a model that relies solely on the idiosyncratic productivity $\epsilon$ to generate labor market statistics would be unable to match the fraction of roughly $17 \%$ of US couples where both individuals are OLF.

The characterization of the competitive equilibrium is standard and is therefore relegated to Appendix 7.3.

\section{Calibration and Steady State Results}

\subsection{Calibration}

In this section, we discuss our choices of parameters and functional forms. All parameter values are also given in Table 7 . We adopt a period utility function for household consumption of the form

$$
u\left(c_{i}, l_{i}\right)=\frac{\left(c_{i}^{\eta} l_{i}^{1-\eta}\right)^{1-\gamma}}{1-\gamma}
$$

We set $\gamma=2$ and choose $\eta$ equal to 0.47 in order to target a ratio of employment to population of $62 \%$ in the steady state (the CPS average for the years 1994 to 2011). ${ }^{15}$ This implies an intertemporal elasticity of substitution $(1-\eta(1-\gamma))^{-1}$ of 0.6803 .

Since the model's horizon is one month, we fix the depreciation rate $\delta$ to 0.0083 . We set the capital share in final output $\alpha$ to 0.36 and we assume that the employed agents spend one-third of their time in market work (hence we set $\bar{h}=0.33$ ). We choose the value for the time preference parameter $\beta$ so that the steady state interest rate $R=1+r-\delta$ is 1.0041 (i.e., the analogue of an annual rate of $5 \%$ ). The resulting value is 0.991 . For the aggregate TFP process $\lambda_{t}$, we follow Chang and Kim (2007) and calibrate it so that the quarterly first order autocorrelation is $\rho_{\lambda}=0.95$ and the conditional standard deviation $\sigma_{\lambda}=0.007$. We use standard techniques to discretize this process to a four state Markov chain. The corresponding monthly values are $0.9748,0.9935,1.0065$, and 1.0252 .

Search Technology and Separation Shocks. As discussed earlier, we adopt a parsimonious representation of the search technology: there are two levels of search intensity that a worker can exert, $s \in\{\underline{s}, \bar{s}\}$. We assign values to $p(\bar{s}, \bar{\lambda}), p(\underline{s}, \bar{\lambda})$, and $\chi(\bar{\lambda})$ in the steady state $(\bar{\lambda}$ denotes the mean of aggregate TFP) in order to match the average worker flows in the US economy. The value of $p(\bar{s}, \bar{\lambda})$ is set to 0.26 , the value of $\left.p_{(\underline{s}}, \bar{\lambda}\right)$ to 0.16 , and the value of $\chi(\bar{\lambda})$ to 0.02 . As we will show in more detail in Section 4.2 , given these values, our model matches flows between the three labor market states well.

\footnotetext{
${ }^{15}$ The assumption that utility is nonseparable is in line with the microevidence of Attanasio and Meghir (1994).
} 
Further on, the time cost of searching is assumed to be of the form

$$
\kappa(s)=\left\{\begin{array}{lll}
0 & \text { if } & s=\underline{s} \\
\kappa & \text { if } & s=\bar{s}
\end{array}\right.
$$

The cost of search parameter for unemployed workers $\kappa$ is chosen to target an unemployment rate of $6.5 \%$ in the aggregate, something which is achieved by $\kappa=0.7$.

Both the arrival rates of job offers and the separation probabilities change with the aggregate state $\lambda$. Our approach, which is similar to Krusell et al. (2012), is to choose the values for these probabilities in recessions and expansions to mimic the patterns of worker flows that we see in the US data. To be more precise, we let $\left(1+x_{p}\right) p(\bar{s}, \bar{\lambda})$ be the largest value of the probability that an unemployed agent gets a job offer associated with the highest level of TFP, and $\left(1-x_{p}\right) p(\bar{s}, \bar{\lambda})$ be the lowest value of the arrival rate. We then choose $p(\bar{s}, \lambda)$ to be uniformly distributed over this interval in order to match the cyclical properties of the UE rate. To construct the values of $p(\underline{s}, \lambda)$ we keep the same $x_{p}$ thus making the ratio of the probabilities for unemployed and OLF workers constant over the business cycle. We follow a similar procedure to construct the nodes of $\chi(\lambda)$ (uniformly distributed over $\left.\left\{\left(1-x_{\chi}\right) \chi(\bar{\lambda}),\left(1+x_{\chi}\right) \chi(\bar{\lambda})\right\}\right)$ though our target in the data in this case is the cyclical component of the EU rate.

Notice that this approach introduces only two parameters $x_{p}$ and $x_{\chi}$. It can only be successful if the cyclical properties of the labor force participation in our model match those of the US data. To understand this point, consider an economy where the LF is fixed. Then by exogenously varying the arrival rates of offers, we could match the UE and EU flow rates and the cyclical properties of employment and unemployment. But since in our model, people can flow in and out of the labor force and labor supply decisions depend on idiosyncratic productivity, exogenous movements in $p(\bar{s}, \lambda) p(\underline{s}, \lambda)$ and $\chi(\lambda)$ do not suffice to match the behavior of all the flow rates. If individuals drop out of the labor force in recessions, then the flows from employment to unemployment may become procyclical in our model, and analogously, the flows from employment to OLF, countercyclical.

Idiosyncratic productivity. The idiosyncratic labor productivity process is based on the empirical labor income literature (see Heathcote et al. (2009)) and is of the form

$$
\log \left(\epsilon_{t}\right)=\rho_{\epsilon} \log \left(\epsilon_{t-1}\right)+v_{\epsilon, t}
$$

The innovations are mean zero processes and $v_{\epsilon, t} \sim \mathcal{N}\left(0, \sigma_{\epsilon}\right)$ ). Moreover, we allow the innovations to be correlated within the household.

To calibrate $\rho_{\epsilon}$ and $\sigma_{\epsilon}$ we use the results of Chang and Kim (2006), who estimate, with data from the PSID, a model that accounts for selection effects (the possibility that participation in employment is not random). They find $\rho_{\epsilon}=0.781$ and $\sigma_{\epsilon}=0.331$ for males in their sample, and $\rho_{\epsilon}=0.724$ and $\sigma_{\epsilon}=0.341$, for females. Since these estimates are similar, and because our model is one of ex ante identical agents, we use the estimates for the male population.

In order to calibrate the correlation of the shocks within the household, we follow the approach of choosing a value such that our economy produces a gap in labor income inside the household that matches the analogous gap in the US data. In particular we calculate that in the PSID data, in couples where both partners work, the average within-couple 
Table 7: The Model Parameters (Monthly Values)

\begin{tabular}{lccc}
\hline Parameter & Symbol & Value & Target \\
\hline Standard Dev. TFP & $\sigma_{\lambda}$ & 0.0041 & \\
AR(1) of TFP shock & $\rho_{\lambda}$ & 0.983 & US DATA \\
Share of Capital & $\alpha$ & 0.33 & \\
Depreciation Rate & $\delta$ & 0.0083 & Normalization \\
Time Working & $\bar{h}$ & 0.33 & R-1 $=.41 \%$ \\
Discount Factor & $\beta$ & 0.9903 & U rate of $6.5 \%$ \\
Search cost & $\kappa$ & 0.7 & CK $(2006)$ \\
Moments $\epsilon$ & $\left\{\sigma_{\epsilon}, \rho_{\epsilon}\right\}$ & $\{0.107,0.979\}$ & \\
Offer Rate: OLF & $p(\underline{s}, \bar{\lambda})$ & 0.16 & Worker Flows \\
Offer Rate: Unemployed & $p(\bar{s}, \bar{\lambda})$ & 0.26 & CPS data \\
Separation Rate & $\chi(\bar{\lambda})$ & 0.02 & Fraction of OLF Couples. \\
Retirement Rate & $\phi_{1}$ & 0.00945 & 0.08 \\
Re-entry Rate & $\phi_{2}$ & & \\
\hline
\end{tabular}

This table shows the calibrated parameters, their values, their associated targets.

gap (the ratio of the highest to the lowest wage) is on the order of 0.7 . When we set the correlation equal to 0.4 , our model produces this value. ${ }^{16} 17$

In Section 4.4, we show that given this calibration, our model produces an AWE that is consistent with our estimates presented in Section 2.3. To understand this point, note that insurance against unemployment risks in our model increases when the two spouses have the same potential labor income. If a family has one employed member and wages are perfectly correlated in the household, then in the event of a job loss, the secondary earner can potentially make up for all of the lost income by getting a job. On the other hand, if there is a huge gap in labor income potential in the household, then secondary earners will not have a big contribution, and in effect joint search becomes meaningless. ${ }^{18}$ Therefore, targeting the gap of labor income in the family is crucial for our model to match the behavioral response of the labor supply of secondary earners. We convert the annual moments into their corresponding monthly values using the procedure of Chang and Kim (2006). We discretize the process using standard techniques.

Retirement. According to the CPS, the monthly probability that an individual

\footnotetext{
${ }^{16}$ To make this point clear, notice that if shocks are perfectly correlated within the family, this gap is essentially zero. On the other hand, if there is no correlation of shocks, then a gap arises endogenously, given the joint employment decisions within the household.

${ }^{17}$ Hyslop (2001) estimates a stochastic process of labor income for US households that features both a fixed effect and a transitory component. He finds a correlation of fixed effects within the family on the order of 0.5 and a correlation of the temporary component of labor income 0.15 . Our specification in 7 is a mixture between the fixed effects and temporary components (see Chang and Kim (2006)). Therefore our choosing a value of .4 seems plausible.

${ }^{18}$ Notice however that insurance against changes in idiosyncratic productivity requires a negative correlation of $\epsilon$ in the family.
} 
becomes retired is 0.009 . We therefore set $\phi_{1}=0.009$. Moreover, we choose $\phi_{2}$ in order to match the percentage of households in the US economy that have both of their members OLF (roughly $16.7 \%$ of couples). The resulting value for $\phi_{2}$ is $0.08 .{ }^{19}$

\subsection{Labor Market Flows}

In this section, we provide information on the model's performance in a number of relevant dimensions. Panel A of Table 8 summarizes the estimated worker flows in the steady state. The data which are our targets are shown in Panel B.

Table 8: Steady State Labor Market Flows

\begin{tabular}{lcccccccc}
\hline & \multicolumn{3}{c}{ A: Model } & & \multicolumn{3}{c}{ B: US Data } \\
\cline { 2 - 4 } \cline { 6 - 8 } & $\mathrm{E}$ & $\mathrm{U}$ & OLF & & $\mathrm{E}$ & $\mathrm{U}$ & OLF \\
\hline $\mathrm{E}$ & 0.953 & 0.011 & 0.036 & & 0.964 & 0.013 & 0.023 \\
$\mathrm{U}$ & 0.257 & 0.643 & 0.100 & & 0.257 & 0.506 & 0.235 \\
$\mathrm{OLF}$ & 0.055 & 0.028 & 0.917 & & 0.046 & 0.026 & 0.929 \\
\hline
\end{tabular}

This table compares monthly labor flows from the steady state model with the corresponding flows in the data. The data are taken from Panel A in Table 3.

The model does a good job in matching the empirical worker flows. It matches perfectly the UE flow rate $(25.7 \%$ in both the data and the model), it matches quite accurately the EU rate ( $1.1 \%$ in the model and $1.34 \%$ in the data), the OLFU flow rate $(2.81 \%$ vs. $2.54 \%$ ), the OLFE flow rate (5.49\% vs. $4.55 \%)$, and the EOLF flow rate $(3.38 \%$ vs. $2.27 \%)$. The model significantly underestimates the UOLF flow rate $(10 \%$ vs. $23 \%$ in the data).

As to the flows out of employment, the model possesses two key mechanisms: the arrival rate of the match shock $\chi(\lambda)$ and the changes in idiosyncratic productivity $\epsilon$. Because $\epsilon$ shocks are persistent, drops in productivity are infrequent in the model, but when they occur they are often accompanied by a transition from employment to OLF. On the other hand, shocks to existing matches can lead to either flows into unemployment or flows to OLF. Both can occur because some households prefer to hold on to their jobs even though they would prefer being OLF rather than unemployed. ${ }^{20}$ For such households, unemployment is a worse state than OLF because searching for job opportunities is a costly activity. Therefore, after they separate due to a $\chi$ shock, they do not search, they become OLF instead. A higher value of the separation rate $\chi$ in the steady state would increase the EU flow rate to match the data but would also increase the flow rate from employment to OLF.

\footnotetext{
${ }^{19}$ In the CPS data, the majority of households with both members OLF are retired households. However the model gives, endogenously, families of two OLF individuals through the idiosyncratic process $\epsilon$. That is, couples where both members have low $\epsilon$ will choose to become OLF. This forces us to set $\phi_{2}$ to a slightly higher value than 0.045 (which is the value that would give $16.7 \%$ retired households).

${ }^{20}$ Garibaldi and Wasmer (2005) refer to this behavior as job hoarding.
} 
In spite of the fact that we set $p(\underline{s}, \bar{\lambda})=0.16$ in our calibration, the model produces an OLFE rate that is close to the US data. This success of the model is due to the fact that families place their unproductive members OLF and as most of these individuals do not want jobs, even if a job becomes available, there is no transition to employment.

Because individual productivity is persistent, and for families wealth is an important determinant of the labor market status, the model generates a transition probability from unemployment to OLF that is roughly 13 percentage points lower than the data. As households with unemployed members run down their wealth, they typically become less likely to give up search and flow to OLF. One way that such a transition may occur is by a drop in productivity, which, as we said, is persistent. This difficulty of models of heterogeneous households in matching the flow rate from unemployment to OLF was also pointed out by Krusell et al. (2011). ${ }^{21}$ In contrast to us, they have a model where each household comprises a single earner. We find that this difference is crucial. To understand why, notice that in the steady state of our model, there are a number of families in the state UU (both members unemployed) or in the state EU (one member employed and the other unemployed). For the UU households, if one member receives a job offer then it is quite likely that the optimal response of the family is to withdraw the other member from the labor force. If both receive a job offer, then it is quite likely that the family will want to allocate its more productive member to work and withdraw the least productive from the labor force. Similarly, in an EU household, an increase in the idiosyncratic productivity of the employed family member may have a powerful wealth effect on the labor supply of the other household member. ${ }^{22}$

\subsection{Employment in the Household}

Table 9 shows the joint labor market status of the two household members in the model. $48 \%$ of the households have both of their members employed, $27.5 \%$ have one employed and one OLF, and $5.5 \%$ have one employed and one unemployed. The counterparts for these statistics in the data are shown in the second row of Table 9 . There are $51.5 \%$ of couples in the EE state and $27 \%$ in the EOLF state. The model underestimates the EE families and overestimates the EU families somewhat. Overall, however, it is quite successful in replicating the data, considering that none of these variables was targeted.

One reason the model fails to match the data perfectly is that we target an employment population ratio and an unemployment rate that correspond to the aggregate statistics over the entire labor force, and not the averages for married individuals. Married couples have, for example, an employment population ratio of roughly $66.5 \%$ as opposed to $62 \%$ which is our target. The difference between these two statistics is driven by the fact that many households in the US have more than just two members counted as part of the LF (for example, children or other adults in the household) ${ }^{23}$ Consider an alternative

\footnotetext{
${ }^{21}$ Krusell et al. (2011) also argue that flows from U to OLF are mismeasured in the data, following the work of Abowd and Zellner (1985). We refer the reader to their paper for details.

22 This intuition appears to be in line with the US data. For example, in married households, male UOLF flow rates are considerably smaller $(14.6 \%)$ than female UOLF flow rates $(27.2 \%)$. Moreover, we can illustrate that joint search and labor supply match the data by considering how a single earner household would behave in our economy. We solved the dynamic program for a bachelor household and computed the transition probabilities for that model. We found that the transition rate from unemployment to OLF is only $3.45 \%$, much lower than our estimated UOLF flow rate of $10 \%$ in the benchmark model.

${ }^{23}$ We already explained that our theory of joint search is one that should apply to every household member, even though the data seem to suggest that the marginal worker for most US households is indeed
} 
calculation for the quantities given in Table 9, one that includes members of the household beyond the husband and the wife. For example, consider a family that consists of three members: an employed husband, an OLF wife, and another individual of at least 16 years of age that is OLF. Denote this household by EOLFOLF. The LF participation in an economy that consists of this household is $33 \%$. Yet if we focus only on the married couple, we get $50 \%$. One way to deal with this difficulty is to break this household into its combinations: three households, two of which are EOLF, and one OLFOLF. By doing this, we get a LF participation in the economy of $33 \%$ (the right number) and a different division of labor market status.

Table 9: Joint Labor Market Status

\begin{tabular}{lcccccc}
\hline Joint Status & EE & E OLF & EU & UU & U OLF & OLF OLF \\
\hline Model & 0.476 & 0.275 & 0.055 & 0.006 & 0.017 & 0.172 \\
Data & 0.515 & 0.270 & 0.033 & 0.002 & 0.009 & 0.167 \\
\hline
\end{tabular}

This table shows the joint labor market status of married couples in the model and in the data. For example, column 3 shows the share of married couples whose household head is employed and whose second household member is out of the labor force. The data are from the CPS 1994-2011.

When we apply this calculation to the CPS data we find that there are $44 \% \mathrm{EE}$ couples and $33 \%$ EOLF couples. Therefore in this case, the model gives more households with both members employed than the US data. Moreover, in the previous section we explained that the joint determination of labor market status in the family is important in matching some of the flow rates as in the US data. We said for instance that models in which households consist of couples perform better in terms of the flow rate from unemployment to OLF than bachelor household models, due to the presence of $E U$ and $U U$ couples. ${ }^{24}$ However, the results in Table 9 show that the model overestimates the fraction of these household types in the population relative to the data. The different calculation of computing these moments however, gives a fraction of $E U$ couples roughly equal to $5 \%$ and a fraction of $U U$ couples of $0.5 \%$, which are close to the model. Thus, by this metric, the model does a very good job in matching the data.

\subsection{The Added Worker Effect}

The empirical analysis in Section 2.3 showed that the probability that the female spouse joins the labor force conditional on her husband's unemployment spell is 8 percentage points higher than the unconditional probability. In our model, we match this value for the contemporaneous added worker effect almost perfectly. The probability that the secondary household earner joins the LF (unconditionally) is $12.2 \%$. Conditional on unemployment of the primary earner, this probability increases to 19.8\%. This implies an AWE of $7.6 \%$ in the model versus $7.8 \%$ in the data.

\footnotetext{
the married wife.

${ }^{24}$ Note that the average flow rates targeted in the previous section corresponded to the entire population aged 16 and above.
} 
Table 10: The Added Worker Effect: Model and Data

\begin{tabular}{ccc}
\hline & LF Participation: Data & LF Participation: Model \\
\hline$\alpha_{-2}$ & 0.0096 & 0 \\
$\alpha_{-1}$ & 0.0215 & 0 \\
$\alpha_{-0}$ & 0.0784 & 0.0760 \\
$\alpha_{+1}$ & 0.0466 & 0.0501 \\
$\alpha_{+2}$ & 0.0339 & 0.0340 \\
\hline
\end{tabular}

The data column shows the estimates in Table 6 . Both in the model and in the data, the coefficients represent the dynamic AWE for families that initially have one member in employment and one member OLF. The employed individual may become unemployed (but not drop out of the LF) and the OLF individual may join the labor force.

Table 10 summarizes the dynamic responses to the family's primary earner's unemployment spell, along with the empirical counterpart that we estimated in Section 2.3. There are several noteworthy features: First, as we discussed previously, since for some households in the data unemployment spells of the primary earner are anticipated, the labor supply responses of secondary earners lead the recorded spell. Indeed, we estimated a statistically significant coefficient $\alpha_{-1}$ of 0.0215 . However, since transitions from employment to unemployment in our model are unanticipated, this cannot generate an added worker effect prior to the occurrence of the spell. Therefore, the model produces an estimate for $\alpha_{-1}$ equal to zero.

Second, we illustrated in Section 2.3 that a large share of households respond to an unemployment shock with a lag. In this case, the household either faces adjustment costs that delay the wife's participation or, for households that have experienced unemployment spells in the previous months, there is a fall in household wealth and therefore a bigger incentive to flow into the labor force as time goes by. In a way, our theory features both of these margins. First, the frictions in the arrival rate of offers that make $\mathrm{U}$ to $\mathrm{E}$ transitions difficult contribute to the fall in wealth resulting from an unemployment spell. Second, though there are no adjustment costs in the model of the same nature as there might be in the data (one can imagine that families might find it difficult to use joint search in the presence of children, for instance), there is a friction that impedes the transition from OLF directly to employment. As we mentioned earlier, some household members prefer to be employed to non-employed but also prefer being OLF than being unemployed. For these individuals, labor market frictions may delay their joining the labor force because moving into the LF means moving directly to employment (i.e., accepting a job offer). ${ }^{25}$ Through these channels, the model matches nearly perfectly the coefficients $\alpha_{+1}$ and $\alpha_{+2}$.

\footnotetext{
${ }^{25}$ To put this differently, notice that what the model captures in this case is a response to spousal unemployment of individuals that prior to the shock did not want jobs, but after the shock want a job even though it is too costly for them to search actively in the labor market: these are individuals that we referred to previously as non-searchers. Unemployment in the household increases the probability that the secondary earner becomes a non-searcher.
} 


\section{Cyclical Properties}

\subsection{Solution Method}

We solve the model with aggregate uncertainty using the bounded rationality approach of Krusell and Smith (1998) whereby agents forecast future prices using a finite set of moments of the distribution $\Gamma_{t}$. In the Appendix, we explain the methodology and show that we get very accurate forecasts, i.e., approximate aggregation holds in our model.

\subsection{Aggregate Labor Market Statistics: Models and Data}

Table 11 shows the model's performance in matching the behavior of the aggregate labor market statistics (employment, unemployment, and labor force participation) over the business cycle. For the sake of convenience, the data which were presented in Section 2 are shown in panel A. The model results are shown in Panel B. The data are time aggregated into quarterly observations, logged and HP filtered with a filtering parameter of 1600 . The model matches the cyclical pattern of aggregate employment and unemployment very well. The relative standard deviation of aggregate employment with output is 0.81 whereas in the data it is 0.77 . For the aggregate unemployment rate, the analogous statistics are 8.08 in the model and 9.01 in the data. Unemployment is very negatively contemporaneously correlated with the GDP, -0.95 in the model and -0.90 in the data. Aggregate employment is procyclical, 0.90 in the model and 0.82 in the data.

Both in the data and in the model, labor force participation is only weakly correlated with output. The correlation coefficient is 0.33 in the data and 0.27 in the model, a near perfect match. Moreover, the relative standard deviation of the LF participation with the GDP is 0.27 in both the model and the data. Thus, the model replicates the data almost perfectly.

Table 11: Quarterly Labor Market Statistics: Data and Models

\begin{tabular}{|c|c|c|c|c|c|c|c|c|c|}
\hline & \multicolumn{3}{|c|}{ A: US Data } & \multicolumn{3}{|c|}{ B: Couple model } & \multicolumn{3}{|c|}{ C: Bachelor model } \\
\hline & $\mathrm{E}$ & $\mathrm{U}$ & $\mathrm{LF}$ & $\mathrm{E}$ & $\mathrm{U}$ & $\mathrm{LF}$ & $\mathrm{E}$ & $\mathrm{U}$ & $\mathrm{LF}$ \\
\hline$\frac{\sigma_{x}}{\sigma_{y}}$ & 0.77 & 9.01 & 0.27 & 0.81 & 8.08 & 0.27 & 0.97 & 7.28 & 0.44 \\
\hline$\rho_{x, y}$ & 0.82 & -0.90 & 0.33 & 0.90 & -0.95 & 0.27 & 0.95 & -0.93 & 0.86 \\
\hline
\end{tabular}

The data are quarterly aggregates and are taken from Table 1. $\frac{\sigma_{x}}{\sigma_{y}}$ is the volatility of $x$ relative to the volatility of the GDP. $\rho_{x, y}$ is the correlation of $x$ with the GDP. Panel B shows the result of a baseline model where each household has two members. Panel $\mathrm{C}$ shows the results of a model in which each household has only one member.

As we explained previously, the success of our model in matching the cyclical properties of employment and unemployment is due to the joint impact of technology shocks and the movements in the arrival rates of job offers and the separation shocks. Our calibration is such that in the worst phase of the cycle the rate $p(\bar{s}, \lambda)$ is as low as $14.3 \%$ and in the peak of the boom it is $37.7 \%$. For the separation shock $\chi(\lambda)$ the analogous values are $2.8 \%$ and $1.2 \%$ respectively. Therefore separation and job finding rates move a lot over 
the business cycle giving rise to volatility in the labor market that is comparable to the volatility in the data. Notice however, that matching the cyclical pattern of employment and unemployment, does not guarantee matching the cyclical behavior of the LF. To see this suppose that LF participation in our model was procyclical but that the inflow of individuals in the LF in expansions was relatively modest in size or, to put it differently, not as volatile as to overwhelm the flows between employment and unemployment. If the job finding probability increases sufficiently in economic expansions then most of these individuals that flow in the LF, can find jobs and become employed. This would add to the volatility of aggregate employment but keep the unemployment rate countercyclical in line with the US business cycle. On the other hand if the flow of individuals into the LF in expansions was very large and very procyclical, then the pool of unemployed could increase in booms therefore making the unemployment rate procyclical, in spite of the large changes in the value of the arrival rate of job offers. Therefore both the volatility of the LF and the cyclical cyclical correlation matter here.

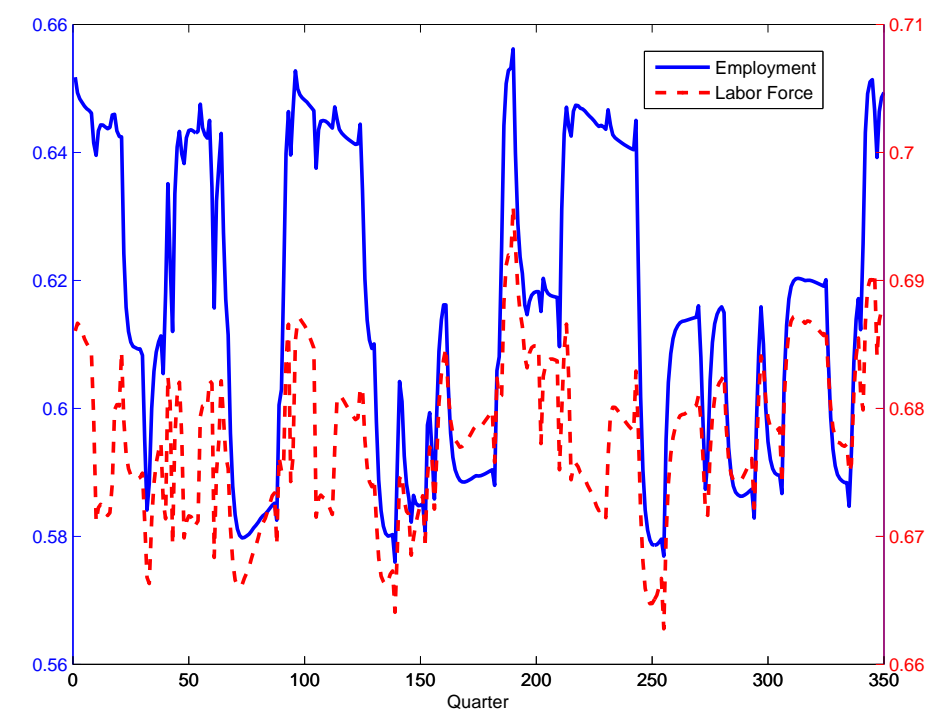

Figure 2: Model Simulations: Labor Force and Employment

This figure shows sample paths from a model simulation. The blue solid line shows the employment population ratio (left scale). The red dashed line shows the labor force participation rate (right scale). The difference between the two is unemployment. The LF is less volatile and less cyclical than employment and unemployment.

Figure 2 shows a sample path from a model simulation. The blue solid line represents the employment to population ratio and the red dashed line represents labor force participation. Notice that there is a common business cycle component for aggregate employment and the LF. In many cases a fall in the employment population ratio is accompanied by a fall in labor force participation. But the bulk of the adjustment is absorbed by an increase in the unemployment to population ratio, which though omitted can be inferred from the Figure. For example, a fall in the employment to population ratio by six percentage points in period 70 in the graph, leads to a fall of the LF participation of less than two percentage points. The unemployment population ratio rises by four percentage points in that period. This important property of the model is a feature of the US business cycle too, as has been shown by Shimer (2012). 
Labor market flows over the business cycle. Table 12 reports the cyclical component of the labor market flows, the correlation with the detrended GDP, and the relative standard deviation in the data (Panel A) and the model (Panel B). Flows from employment to unemployment are very countercyclical and volatile. And flows from unemployment to employment are procyclical and also volatile at business cycle frequencies. The model matches the business cycle properties of these statistics. The contemporaneous correlation with the GDP of the UE rate is -0.81 in the model and its -0.83 in the data. The analogous quantity for the UE rate is 0.91 in the model and 0.84 in the data. Moreover, in terms of volatility the model produces moments that are very close to the US data. Notice that matching the correlation of these transition rates with aggregate output requires LF participation to not drop abruptly in recessions. Our model generates a transition from employment to unemployment when the $\chi(\lambda)$ shock hits. But increases in the arrival rate of the match quality shock in recessions are necessary but not sufficient for the EU rate to be countercyclical. In fact for a large fraction (nearly 45\%) of the employed population, match quality shocks lead to a transition from employment directly to OLF, and therefore more frequent separation shocks could induce agents to abandon the LF in recessions. Instead, Table 12 shows that in our model individuals choose to drop out of the LF from employment in expansions which is a feature that is in line with the US business cycle. The correlation of the EOLF rate with the GDP is positive, though the model produces a value 0.1 that falls short of the US data (0.51).

The OLFE flows are more frequent in expansions and OLFU flows more frequent in recessions. The model matches this property of the US business cycle by fluctuations in the arrival rate of offers to OLF workers. As the value of the arrival rate $p(\underline{s}, \lambda)$ increases in expansions, more OLF individuals receive offers. Given that some of these agents are willing to take up on these offers and become employed, there is an increase in the OLFE probability in expansions. Analogously the drop in $p(\underline{s}, \lambda)$ in recessions means that most of these individuals are unable to receive offers and rather have to flow to unemployment in order to become employed. ${ }^{26}$ The overall flow rate between OLF to in the LF (joint OLFE and OLFU transitions) is acyclical. We compute that the correlation of this overall rate with the GDP is -0.03 . In the US data the analogous statistic is -0.10 . Hence our model can match the properties of the flows into the LF over the business cycle.

Finally notice that where the model does not perform well is in matching the cyclical properties of the UOLF rate. The model produces a negative correlation with the GDP of -0.35 , whereas in the data the correlation is positive 0.75 . As we discussed earlier the UOLF rate is the only transition probability that our model has a difficulty in matching. We showed that the flow rate that is generated by the model is more than $50 \%$ smaller than the flow rate in the data. For this reason, even though the UOLF rate is countercyclical, LF participation does not drop in recessions. There is obviously a missing mechanism from our theory that makes it difficult for us to match both the mean and the cyclical pattern of this quantity. One such mechanism could be an unemployment insurance scheme in

${ }^{26}$ In the literature the procyclicality of the OLFE rate is usually attributed to time aggregation. The idea is that OLFE transitions are the result of a flow from OLF to unemployment and a flow from unemployment to employment over a month. Because the statistical agency does not observe the unemployment spell, the transition is recorded as a direct flow from OLF to employment. In expansions unemployed workers are more likely to receive offers. Therefore the likelihood that an unemployment spell is not observed is higher and the OLFE probability increases. In recessions the converse holds. Intervening unemployment spells are more likely to be observed (see Shimer (2012) for details). 
Table 12: Cyclical Behavior of Labor Market Flows

\begin{tabular}{lcccccc}
\hline A: US Data & EU & EOLF & UE & UOLF & OLFE & OLFU \\
\hline$\frac{\sigma_{x}}{\sigma_{y}}$ & 6.14 & 3.70 & 6.38 & 3.85 & 4.58 & 5.17 \\
$\rho_{x, y}$ & -0.83 & 0.51 & 0.84 & 0.75 & 0.62 & -0.76 \\
\hline B: Model & EU & EOLF & UE & UOLF & OLFE & OLFU \\
\hline$\frac{\sigma_{x}}{\sigma_{y}}$ & 5.89 & 2.92 & 6.64 & 2.45 & 2.56 & 5.27 \\
$\rho_{x, y}$ & -0.81 & 0.10 & 0.91 & -0.35 & 0.75 & -0.91 \\
\hline
\end{tabular}

The flow rates are constructed from the CPS. $\frac{\sigma_{x}}{\sigma_{y}}$ is the volatility of $x$ relative to the volatility of the GDP. $\rho_{x, y}$ is the correlation of $x$ with the GDP. Details about the data can be found in Table 1.

our economy. This would make the UOLF rate more procyclical if, for example, the government extended benefits in some recessions (as is the case in the US, see Fujita (2010)) or if more workers applied for benefits in recessions. ${ }^{27}$ We leave this interesting area for future reserach.

Business cycle for primary and secondary earners. Table 13 shows our model's prediction for the labor market behavior of the households' primary earners in Panel A and of its secondary earners in panel B. Our definition is that the primary earner is the household member that has the largest labor income potential. Panel A shows that primary earners' employment and unemployment is more volatile, but LF participation is less volatile. For this group the employment to unemployment margin is more relevant and flows out of the LF are less frequent. However, when they do occur they are procyclical. Secondary earners on the other hand have a countercyclical LF participation. The correlation between participation for this group and the GDP is -0.29 . Participation is volatile whereas employment is not and also for these individuals aggregate employment is not very correlated with economic activity (0.43 correlation with GDP).

Table 13: Business Cycle Statistics of Primary and Secondary Earners in the Model

\begin{tabular}{|c|c|c|c|c|c|c|}
\hline & \multicolumn{3}{|c|}{ A: Primary Earners } & \multicolumn{3}{|c|}{ B: Secondary Earners } \\
\hline & $\mathrm{E}$ & $\mathrm{U}$ & $\mathrm{LF}$ & $\mathrm{E}$ & $\mathrm{U}$ & $\mathrm{LF}$ \\
\hline$\frac{\sigma_{x}}{\sigma_{y}}$ & 1.13 & 8.45 & 0.26 & 0.60 & 7.34 & 0.50 \\
\hline$\rho_{x, y}$ & 0.98 & -0.95 & 0.80 & 0.43 & -0.93 & -0.29 \\
\hline
\end{tabular}

The primary earner is the household member with the highest potential labor income. Analogously, secondary earners have the lower potential income.

\footnotetext{
${ }^{27}$ Note that workers that claim benefits are counted as unemployed by the BLS.
} 
The joint insurance motive explains these patterns. Flowing into the LF to provide insurance makes participation of secondary earners countercyclical, but also weakens the correlation of aggregate employment with economic activity. Quite remarkably in the US data there is a similar pattern for married men and married women. On the one hand, married men have more volatile employment and unemployment aggregates, and less volatile LF participation. The model, however, does not capture the near zero correlation of male LF participation. On the other hand, married women have a countercyclical participation in the LF (-0.22 correlation with GDP) and an aggregate employment that has a contemporaneous correlation of 0.43 with economic activity. These predictions of the model are in line with the US data that were shown in Section 2.

\subsection{The Role of Families: Bachelor vs. Couple Models}

This Section addresses the role of family insurance in the cyclical behavior of the aggregate labor market. We ask the following question "If we remove joint search from the economy how would labor force participation behave over the business cycle?" To answer this question we assume that each household instead of being formed by a couple is inhabited by a bachelor agent. This model is the standard framework of heterogeneous agents and wealth accumulation, but with frictions and three labor market states. ${ }^{28}$

The implications of this model for the aggregate labor market are shown in Panel C of Table 11. Aggregate unemployment has a contemporaneous correlation with the GDP of -0.93, aggregate employment of 0.95 and therefore are similar to the results from our benchmark economy. However, labor force participation now is very procyclical. It has a correlation of 0.86 with economic activity considerably higher than the US data and our benchmark model with couples households. Moreover, it is considerably more volatile than both the data and the benchmark model. These results imply that family self insurance through joint search is crucial in matching the cyclicality of the US labor force. When we remove families from the model we get a very procyclical participation.

Recently the work of Krusell et al. (2012) has shed light on how incomplete market models with bachelor households fare in matching the labor market moments. They emphasize separately the role of shocks to frictions (movements in $\chi(\lambda)$ and $p(s, \lambda)$ ) which they view as shocks to the demand for workers, and shocks to total factor productivity, which give rise to fluctuations that they attribute to labor supply. They explain that shocks to frictions lead to a countercyclical participation (induce agents to join the LF in recessions) whereas shocks to TFP do the opposite, they generate a very procyclical LF. When they put the two together in their model they get a correlation of the LF with the GDP of 0.54 which is not far off the data target.

Our approach is similar to theirs. We have the same sources of aggregate uncertainty (shocks to separation and arrival rates and TFP shocks). But there are two important differences. First, our benchmark model features couples. Second, search is costless in their model leading to a big difference in the criterion of LF participation. Krusell et al. (2012) assume that OLF are all agents that do not want to take up on a job offer if a job offer is made. LF participants are all those individuals that want jobs and given their level

\footnotetext{
${ }^{28}$ In solving for equilibrium we re-calibrated some of the model parameters. As one would anticipate $\beta$ is set at a lower value to match the average interest rate target, due to the higher incentive to accumulate precautionary savings with bachelor households. The value of $\eta$ is set equal to 0.45 and the value of the separation cost $\chi(\bar{\lambda})$ is 0.023 rather than 0.02 . Under aggregate uncertainty we used the same process for TFP and the arrival rates $p(s, \lambda)$ as we did in the benchmark model.
} 
of idiosyncratic productivity, would prefer to work if they received an offer. In terms of our notation they set $p(\underline{s}, \lambda)=p(\bar{s}, \lambda)$. In contrast, we consider as LF participants those individuals that are either employed or search actively in the labor market. This extra margin (unemployment with costly search) is the source of the difference to the results of our bachelor economy.
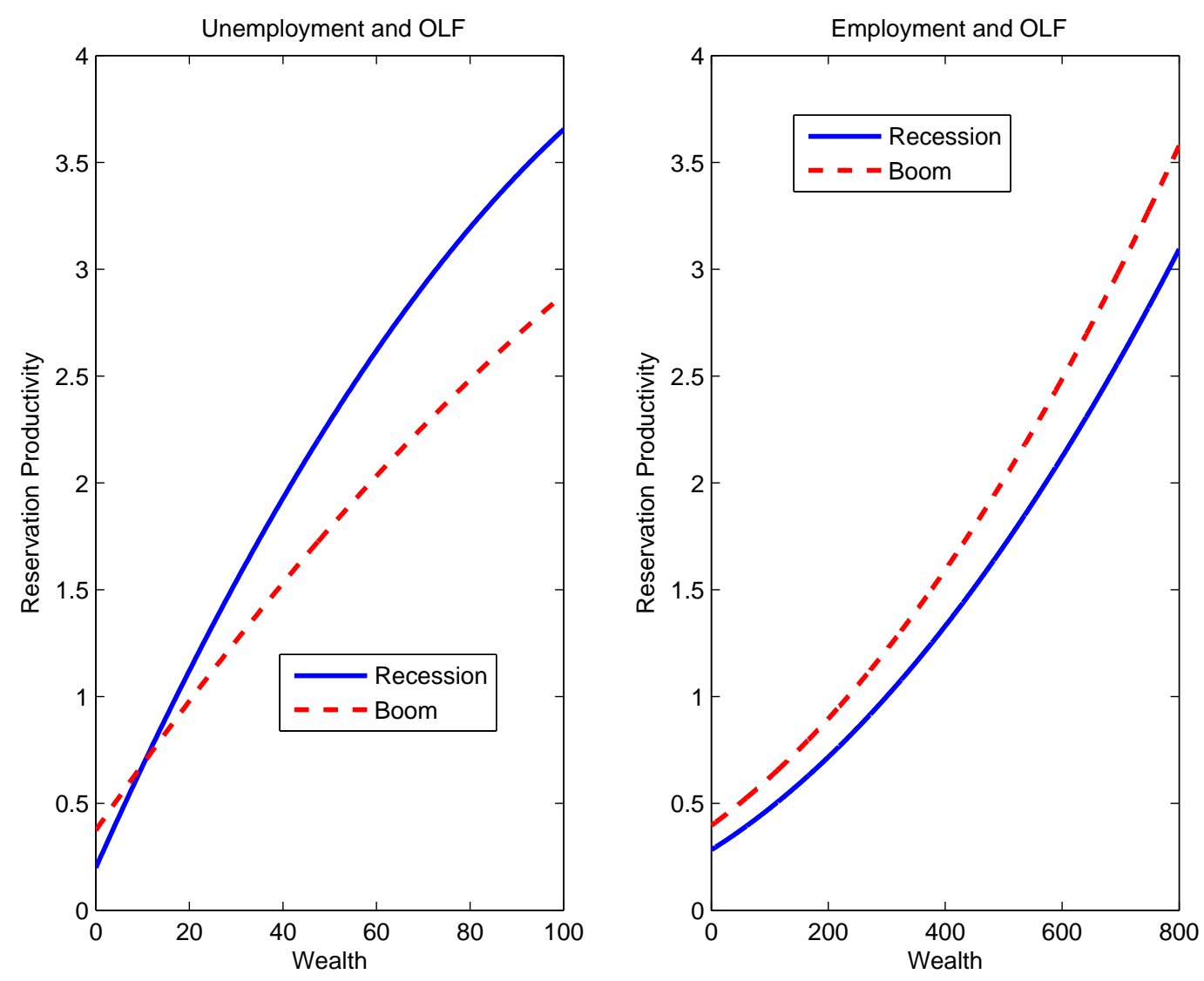

Figure 3: Reservation Wage Rules: Bachelor Model

These figures show the reservation productivities in the bachelor model. The left panel shows the productivity level at which non-employed individuals are indifferent between searching, which is costly, and being OLF. At productivity levels above (below) the reservation level, they will search (be OLF). The reservation productivity is increasing in wealth because richer agents can afford to forgo labor income more easily. The right panel shows the reservation productivity for individuals that have a job. The left panel shows that the reservation productivity for very poor agents is lower in booms than in recessions. This is due to the fact that the probability of finding a job is lower in a recession. The converse holds for rich agents. Their reservation productivity is higher because success is less likely and they can afford to wait. The left panel shows no such intersection. Wages are higher in a boom, therefore agents always prefer to work in a boom.

To illustrate this point further, we plot the reservation wage policy rules from the singles model in Figure 3. The left panel shows the level of productivity $\epsilon$ that induces a non-employed individual to join the labor force (comparison is between unemployment 
and OLF value functions) as a function of household wealth. It slopes upwards because search is costly. ${ }^{29}$ The right panel shows the reservation wage at the employment vs. non employment margin. In this case there is always a level of productivity within the support of $\epsilon$ that induces the agent to remain employed, even though the same agent, if she were to lose her job, would flow out of the LF. Thus, this economy features job hoarding (see Garibaldi and Wasmer (2005)).

The mechanism by which a model without a distinction between unemployed and OLF individuals can produce a countercyclical LF participation is illustrated in the right panel. The red (dashed) line that represents booms is above the blue (solid) line which represents recessions. In recessions individuals are more willing to hold jobs, since jobs are harder to find and also because separation shocks are larger and agents wait for the arrival of such a shock to become non-employed. By contrast in the policy rule in the LHS of the Figure, for the most part of the state space individuals prefer being OLF than being unemployed in recessions. When separations shocks arrive at a higher pace in a recession, individuals would rather drop OLF. This makes the E to OLF worker flow very countercyclical in a bachelor model with costly search which is in contrast to the US data.

Decision rules in couples households. Figure 4 shows the policy rules for the benchmark couple model. The top panels plot the decision rule for unemployment vs. OLF for an individual that has an employed partner (left), and an individual with a non-employed partner (right). The bottom panels plot the employment to non-employment decision rules. Notice that over the same region of the state space the reservation wage policies are different for the couple household relative to the single household; essentially couples need twice the amount of wealth to have a reservation productivity that is similar to that of singles.

There are two properties of these decisions rules that explain why the couple household model performs better in matching the data. The first is that whenever a family with one employed and one OLF member suffers from an unemployment shock (with a higher probability in a recession), the OLF member joins the LF to provide insurance. This is illustrated by the fact that having a spouse that is non-employed, extends the region over which an individual prefers unemployment to being OLF. Moreover, Figure 5 shows the policy rules in recessions (left) and booms (right). The solid blue lines correspond to the case in which the partner is employed and the dashed lines to the case in which the partner is non-employed. The graph illustrates that reservation productivities drop when the partner loses his job and the fall is considerably larger in recessions.

The second important feature is that the region where the red (dashed) line lies above the blue line is more than twice as large in the couple model as in the single model. Practically this means that there is more scope for labor force participation to increase in recessions in the couples model. This effect is further reinforced by the fact that models with bachelors households give rise to a strong precautionary savings motive and to a strong wealth effect on labor force participation. The strong wealth effect is not a feature of the US data as documented by Chang and Kim (2007). In equilibrium most OLF individuals in the single model hold a considerable amount of savings and therefore

\footnotetext{
${ }^{29}$ Notice that we consider a more narrow region of the state space in that graph. As wealth increases further the policy rule becomes flat in which case the agent has enough wealth so that even if productivity is at the upper bound of our assumed process, she prefers OLF to unemployment.
} 

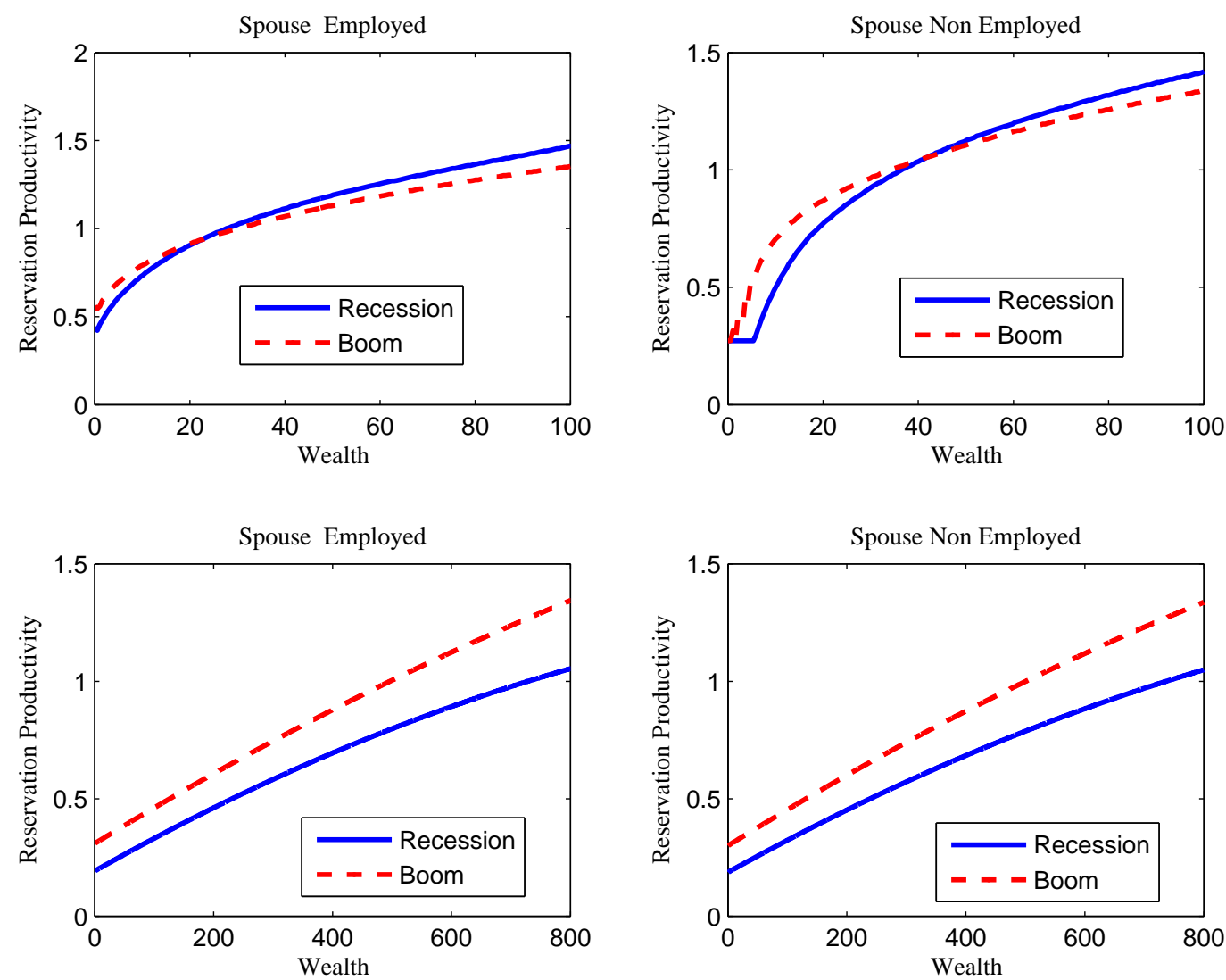

Figure 4: Reservation Wage Rules: Couple Model

These figures show the reservation productivities in the couple model. The left panels show the reservation productivity conditional on the spouse's being employed, while the right panels are conditional on the spouse's being non-employed. The top two panels show the reservation productivity at which a non-employed individual is indifferent between searching, which is costly, and being OLF. The bottom two panels show the reservation productivity for employed individuals. One important difference from the previous figure is that the intersection for non-employed individuals (top panels) is at much higher wealth levels than in the bachelor economy. Thus, the LF participation of secondary earners is more countercyclical. 

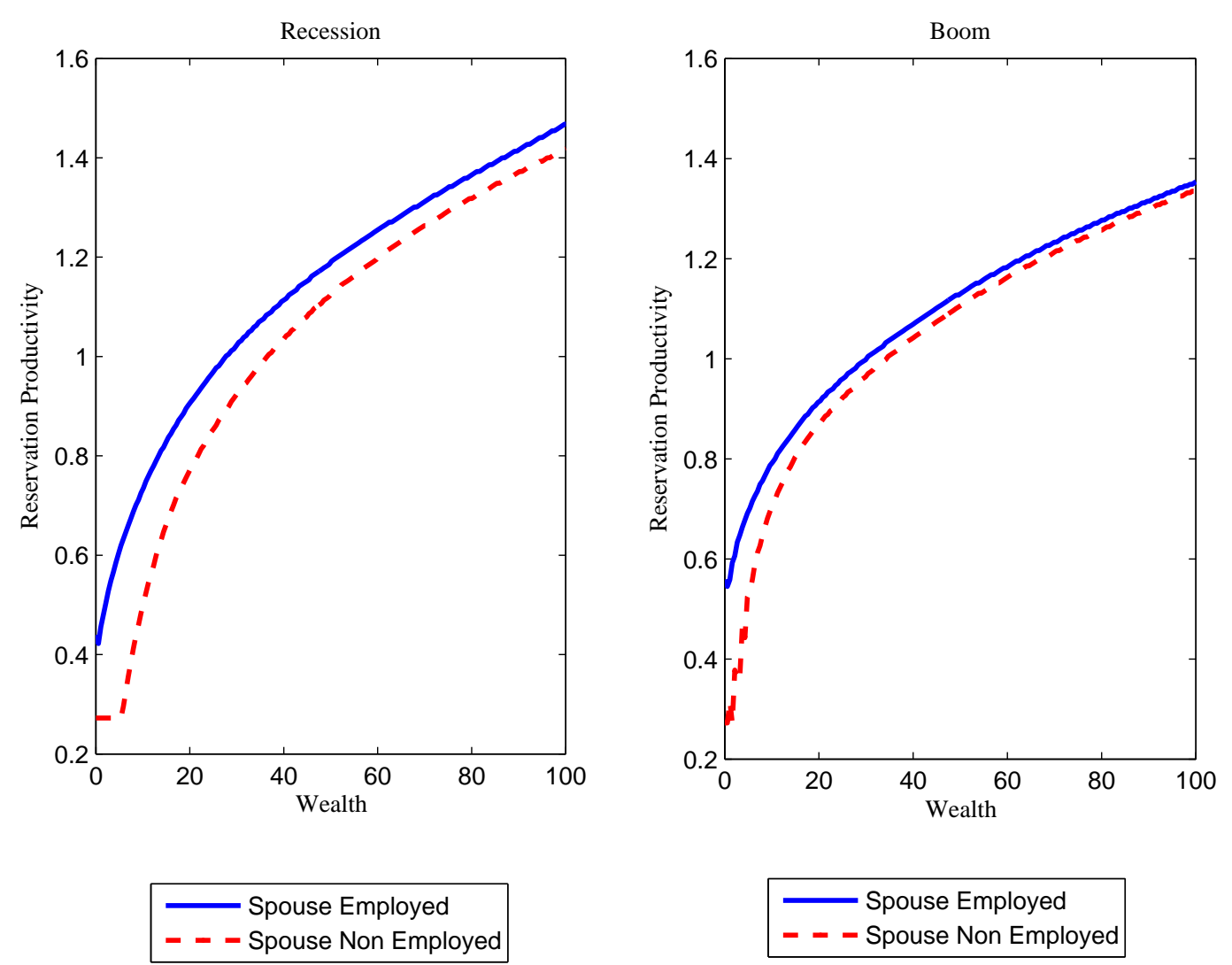

Spouse Employed

- - - Spouse Non Employed

Figure 5: Impact of Job Loss on the Reservation Wage: Couple Model

These figures show the reservation productivity for the secondary household member in booms (left panel) and recessions (right panel). The reservation productivity is always lower when the spouse has no job, because then the household has no market income. This effect is more pronounced during recessions, making the LF participation of secondary earners more countercyclical. 
they lie far away from the region in which joining the LF is more likely in a recession, i.e., the region near the borrowing constraint. ${ }^{30}$ By contrast couples households use less precautionary savings and the implied wealth effect on participation is weaker. To put this differently, in a model in which households consist of couples, being OLF is the result of specialization in the household and therefore implies the presence of a main earner. In a single household model being OLF, however, requires a substantial amount of wealth. Our model matches the fraction of households with one employed and one OLF member, and also matches the AWE as in the US data. Therefore, it is unlikely that it overestimates the importance of these channels.

\section{Conclusion}

This paper shows that family self insurance is important in matching the business cycle properties of the aggregate labor market in the US. We show that US households use joint search in order to insure against the impact of a job loss in the family. We present a theoretical framework that features incomplete financial markets and frictional labor markets. The crucial innovation in our model is that households consist of couples whose members decide jointly whether to work, become unemployed and look for jobs which is costly, or flow out of the labor force.

Differences in idiosyncratic labor income give rise to primary and secondary earners within the household in our model. Families specialize and allocate their most productive member to the labor market, though search frictions partly prevent them from doing so. However, despite this selection effect, secondary earners still provide valuable insurance against unemployment risk to household income. We show this mechanism in the data and in the model. Our model matches the cross sectional labor market evidence, e.g. the labor market flows, the intrahousehold specialization in terms of labor market states as well as the added worker effect. Through matching these features we demonstrate that the model is able to capture the behavior of the marginal household in the US. As a result, our model is able to explain the cyclical properties of the aggregate labor market in the US, and in particular the low cyclical correlation of labor force participation with economic activity. We demonstrate that family self insurance is an important mechanism in order to accomplish this.

\footnotetext{
${ }^{30}$ This is a well known property of models of heterogeneous agents and wealth accumulation, that most agents hold sufficient wealth to behave as permanent income agents (see Krusell and Smith (1998)).
} 


\section{References}

Abowd, J. and A. Zellner (1985). Estimating gross labor-force flows. Journal of Business E Economic Statistics 3(3), 254-283.

Attanasio, O., H. Low, and V. Sanchez-Marcos (2005). Female labor supply as insurance against idiosyncratic risk. Journal of the European Economic Association 3(2-3), 755764.

Attanasio, O., H. Low, and V. Sanchez-Marcos (2008). Explaining changes in female labor supply in a life-cycle model. American Economic Review 98(4), 1517-1552.

Borjas, G. and S. Rosen (1980). Income prospects and job mobility of younger men. Research in Labor Economics 3, 159-181.

Chang, Y. and S. Kim (2006). From individual to aggregate labor supply: A quantitative analysis based on a heterogeneous agent macroeconomy. International Economic Review 47(1), 1-27.

Chang, Y. and S.-B. Kim (2007). Heterogeneity and aggregation: Implications for labormarket fluctuations. American Economic Review 97(5), 1939-1956.

Cubeddu, L. and J. Ríos-Rull (2003). Families as shocks. Journal of the European Economic Association 1(2-3), 671-682.

Cullen, J. and J. Gruber (2000). Does unemployment insurance crowd out spousal labor supply? Journal of Labor Economics 18(3), 546-572.

Engen, E. and J. Gruber (2001). Unemployment insurance and precautionary saving. Journal of Monetary Economics 47(3), 545-579.

Fujita, S. (2010). Effects of the UI Benefit Extensions: Evidence from the Monthly CPS. Federal Reserve Bank of Philadelphia.

Gallipoli, G. and L. Turner (2008). Disability in Canada: A longitudinal household analysis. mimeo.

Gallipoli, G. and L. Turner (2009). Household Responses to Individual Shocks: Disability and Labor Supply. mimeo.

Garibaldi, P. and E. Wasmer (2005). Equilibrium search unemployment, endogenous participation, and labor market flows. Journal of the European Economic Association 3(4), $851-882$.

Guler, B., F. Guvenen, and G. Violante (2012, May). Joint-search theory: New opportunities and new frictions. Journal of Monetary Economics 59(4), 352-369.

Hall, R. (2005). Employment fluctuations with equilibrium wage stickiness. American Economic Review 1, 50-65.

Hall, R. and P. Milgrom (2008). The limited influence of unemployment on the wage bargain. The American Economic Review 98(4), 1653-1674.

Heathcote, J., K. Storesletten, and G. Violante (2009). Quantitative macroeconomics with heterogeneous households. Annu. Rev. Econ. 1(1), 319-354. 
Heathcote, J., K. Storesletten, and G. Violante (2010). The macroeconomic implications of rising wage inequality in the United States. Journal of Political Economy 118(4), $681-722$.

Hyslop, D. (2001). Rising US earnings inequality and family labor supply: The covariance structure of intrafamily earnings. American Economic Review 91 (4), 755-777.

Jones, S. and W. Riddell (1998). Gross flows of labour in Canada and the United States. Canadian Public Policy/Analyse de Politiques, 103-120.

Jones, S. R. G. and W. C. Riddell (1999, January). The measurement of unemployment: An empirical approach. Econometrica 67(1), 147-162.

Krusell, P., T. Mukoyama, R. Rogerson, and A. Şahin (2011). A three state model of worker flows in general equilibrium. Journal of Economic Theory 146(3), 1107-1133.

Krusell, P., T. Mukoyama, R. Rogerson, and A. Şahin (2012). Is labor supply important for business cycles? NBER Working Paper 177r79, 1-57.

Krusell, P. and A. A. Smith (1998). Income and wealth heterogeneity in the macroeconomy. The Journal of Political Economy 106(5), 867-896.

Lucas, R. J. and E. C. Prescott (1974, February). Equilibrium search and unemployment. Journal of Economic Theory 7(2), 188-209.

Lundberg, S. (1985). The added worker effect. Journal of Labor Economics 3(1), 11-37.

Mazzocco, M. (2007). Household intertemporal behaviour: A collective characterization and a test of commitment. Review of Economic Studies $74(3), 857$.

Merz, M. (1995). Search in the labor market and the real business cycle. Journal of Monetary Economics 36(2), 269-300.

Mortensen, D. and E. Nagypal (2007). More on unemployment and vacancy fluctuations. Review of Economic Dynamics 10(3), 327-347.

Mortensen, D. and C. Pissarides (1994). Job creation and job destruction in the theory of unemployment. The Review of Economic Studies 61(3), 397-415.

Nagypál, É. (2005). On the extent of job-to-job transitions. mimeo.

Shimer, R. (2004). Search intensity. mimeo.

Shimer, R. (2005). The cyclical behavior of equilibrium unemployment and vacancies. American Economic Review 95(1), 25-49.

Shimer, R. (2012). Reassessing the ins and outs of unemployment. Review of Economic Dynamics 15(2), 127-148.

Spletzer, J. (1997). Reexamining the added worker effect. Economic Inquiry 35(2), $417-427$.

Tripier, F. (2004). Can the labor market search model explain the fluctuations of allocations of time? Economic Modelling 21(1), 131-146. 
Veracierto, M. (2008). On the cyclical behavior of employment, unemployment and labor force participation. Journal of Monetary Economics 55(6), 1143 - 1157.

Wang, C. and S. Williamson (2002). Moral hazard, optimal unemployment insurance, and experience rating. Journal of Monetary Economics 49(7), 1337-1371.

Young, E. (2010). Solving the incomplete markets model with aggregate uncertainty using the Krusell-Smith algorithm and non-stochastic simulations. Journal of Economic Dynamics and Control 34(1), 36-41. 


\section{Appendices}

\subsection{Data Description and Variables}

CPS: The Current Population Survey (CPS) is a monthly survey of about 60,000 households (56,000 prior to 1996 and 50,000 prior to 2001), conducted jointly by the Census Bureau and the Bureau of Labor Statistics. Survey questions cover employment, unemployment, earnings, hours of work, and other and a variety of demographic characteristics such as age, sex, race, marital status, and educational attainment. Although the CPS is not an explicit panel survey, it does have a longitudinal component that allows us to construct the monthly labor market transitions used in Section 2 of the paper. Specifically the design of the survey is such that the sample unit is interviewed for four consecutive months and then, after an eight-month rest period, interviewed again for the same four months one year later. Households in the sample are replaced on a rotating basis, with one-eighth of the households introduced to the sample each month.

Given the structure of the survey we can match roughly three-quarters of the records across months. Unfortunately, there is some sample attrition from individuals who abandon the survey. Using these matched records, we calculate the gross worker flows that we report in Section 2. ${ }^{31}$ Our sample covers the period 1994-2011. The flows are estimates of a Markov transition matrix (as in Table 3) where the three states are employment, unemployment and out of the labor force.

We use the CPS classification rule to assign each member of a household to a labor market state; This rule is as follows: Employed agents are those who did (any) work for either pay or profit during the survey week. ${ }^{32}$ Unemployed are those who do not have a job, have actively looked for work in the month before the survey, and are currently available for work; 'Actively looking' means that respondents have used one or more of the nine search methods considered by the CPS (6 methods prior to 1994) such as sending out resumes, answering adds, contacting a public or private employment agency etc. ${ }^{33}$ Individuals who search passively by attending a job training program or simply looking at adds are not considered as unemployed because these methods, according to the CPS, do not result in potential job offers. Finally, out of labor force are all agents who are neither employed nor unemployed (based on the above definitions). Given the classification we calculate the conditional probability that an agent who is in state $i$ in the previous month (interview date) is in state $j$ this month, where $i, j \in\{E, U, O L F\}$. We use the household weights provided by the CPS so that these objects are representative of the US population and we remove seasonal effects using a ratio to moving average procedure. The entries in Table 3 are the averages of the gross worker flows that we obtain over the sample period.

\subsection{Sample Selection}

We briefly explain our sample selection and methodology used to run the dynamic AWE equation in Section 2.3. We are interested in estimating equation 1 which we repeat here for convenience.

\footnotetext{
${ }^{31}$ In our investigation we use the public micro-data files from the NBER web site. Our approach is similar to that used by Shimer (2012).

${ }^{32}$ This includes all part-time and temporary work, as well as regular full-time, year-round employment.

${ }^{33}$ Workers on temporary layoff who expect to be recalled are counted as unemployed no matter if they search actively.
} 


$$
\begin{aligned}
\text { Transition }_{i, t} & =\sum_{\tau=-2}^{\tau=+2} \alpha_{\tau} I(\text { Husband Spell in } t+\tau)+ \\
& +Z_{t, i} \delta+\text { Time Dummies }+\epsilon_{i, t}
\end{aligned}
$$

The variable $I$ (Husband Spell in $t+\tau$ ) takes the value one if an employment to unemployment transition occurred between in period $t+\tau$ and the value zero otherwise. The regression estimates the likelihood that the wife will join the LF (Transition ${ }_{i, t}$ is a dummy variable with the value one if she does) given that the husband has suffered an unemployment spell in period $t+\tau$. The results presented in Section 2.3 refer to the population of married couples aged 25-55 covering the period 1994-2011. Moreover, we have dropped all households where the male spouse flows out of the labor force at any point in time. This is not at all restrictive given our sample selection criteria.

Given the design of the survey (see previous paragraph) we have only four consecutive months of observations for a couple. We therefore compute the coefficients $\alpha_{\tau}$ for $\tau \in$ $\{-2,2\}$ in order to avoid having to deal with censoring issues that would complicate the analysis. Over a month we observe the labor market status of the husband and the wife. Female spouses can be in the LF if they are employed or unemployed and out of the LF otherwise. Similarly, husbands can be employed or unemployed at any point in time. We keep only couples with 4 consecutive observations. Therefore, we construct three transitions for the husband and the wife across labor market states. In Figure 6, we represent the possible histories of the husband in our sample.

In panel A of Figure 6 the husband is employed initially and can either be employed or unemployed after the first month. To understand how we create the variable $I$ (Husband Spell in $t+\tau$ ) take the history $\{E E, E E, E U\}$ according to which there is an unemployment spell in the family on the fourth month. In this case if we consider the wife's labor force participation between months one and two, $I$ (Husband Spell in $t+2$ ) takes the value one (there is an unemployment spell in two periods) and $I$ (Husband Spell in $t+1$ ) and $I$ (Husband Spell in $t+0$ ) take the value zero. In the next period (between months 2 and 3 ) it is $I$ (Husband Spell in $t+1$ ) that takes the value one and all other dummies are set equal to zero.

A subtle point is how to deal with, for example, a history of the form $\{E U, U U, U E\}$. According to this history the male spouse suffered an unemployment spell in the first period, remained unemployed for two months and then finally found a job in the 4th month of our sample. Naturally we have two options: either to drop the last observation or keep it in the sample and use to estimate the effect of an $E U$ transition that occurred two months ago in the family. In the text we chose to do the latter. That is in spite of the fact that the husband finding a job will probably reduce wifes incentive to join the LF, we treat this observation the same way that we treat a $U U$ transition. The reason is that given that the theory suggests that a household that went through two months of unemployment will have suffered from a considerable drop in resources, there will still be an AWE. Here we will illustrate how the results change when couples whose primary earner finds a job are dropped from our sample. In the Tables we represent the relevant histories with an upper bar at the last node. Further on, note that because we want to estimate the effect of the $E U$ transition on female labor force participation the contemporaneous dummy for 

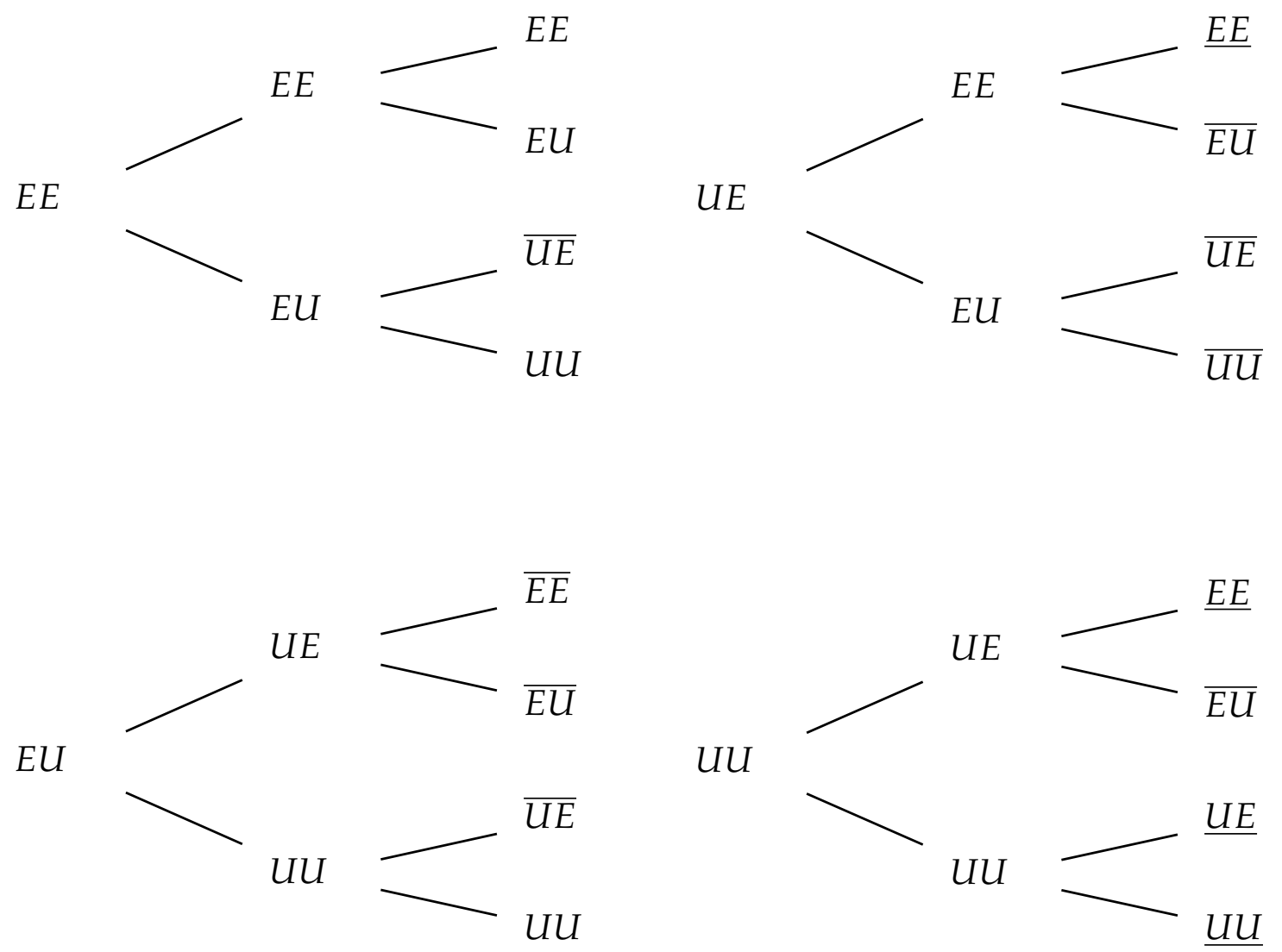

(a) Initial state E

(b) Initial state U

Figure 6: Sample Selection in the Estimation of the Added Worker Effect

These figures show the way we selected the sample for the estimation of the dynamic added worker effect. Panel (a) shows histories starting with an employment spell of the husband. Panel (b) shows histories starting with an unemployment spell. The upper bars at terminal nodes denote histories which are dropped in Column 2 of Table 14 and 15, that is, histories with a recorded unemployment to employment transition. Underscores denote histories that are dropped in every model run to estimate the dynamic AWE. 
Table 14: Dynamic Added Worker Effect: Labor Force Participation

\begin{tabular}{lccccc}
\hline & $\mathrm{EU}_{m}$ & $\mathrm{EU}_{m}$ & Loss $_{m}$ & Quit & Layoff $_{m}$ \\
\hline$\alpha_{-2}$ & 0.0096 & .01439 & 0.01432 & 0.0144 & .0143 \\
& $(0.0086)$ & $(0.0089)$ & $(0.0089)$ & $(0.0089)$ & $(0.0089)$ \\
$\alpha_{-1}$ & $0.02157^{* * *}$ & $.0233^{* * *}$ & $0.0233^{* * *}$ & $0.0234^{* * *}$ & $0.0234^{* *}$ \\
& $(0.00607)$ & $(0.0072)$ & $(0.0072)$ & $(0.0072)$ & $(0.0072)$ \\
$\alpha_{-0}$ & $0.0784^{* * *}$ & $.0839^{* * *}$ & $0.1170^{* * *}$ & $0.1145^{* *}$ & $0.0335^{* *}$ \\
& $(0.00496)$ & $(0.0065)$ & $(0.0093)$ & $(0.0239)$ & $(0.0104)$ \\
$\alpha_{+1}$ & $.0466^{* * *}$ & $.05405^{* * *}$ & $0.06057^{* * *}$ & $0.0887^{* *}$ & $0.0406^{*}$ \\
& $(0.00608)$ & $(0.0100)$ & $(0.0142)$ & $(0402)$ & $(0.0188)$ \\
$\alpha_{+2}$ & $0.0339^{* * *}$ & $.0300^{*}$ & $0.05344^{* *}$ & -0.0525 & -0.0304 \\
& $(0.0084)$ & $(0.01575)$ & $(0.0208)$ & $(0.0537)$ & $(0.0360)$ \\
$\mathrm{R}^{2}$ & 0.007 & 0.066 & 0.066 & 0.062 & 0.062 \\
Observations & 441,785 & 437,475 & 435,680 & 434,091 & 435,008 \\
\hline
\end{tabular}

This table shows the percentage point increase in the probability that a wife joins the labor force if her husband has made (will make) a transition from employment to unemployment two months ago, one month ago, this month, next month, or the month thereafter. $\left.{ }^{* * *}\right]$ Significant at or below 1 percent. $\left.{ }^{* *}\right]$ Significant at or below 5 percent. [*] Significant at or below 10 percent.

the $U U$ state is set equal to zero. That is, whenever the husband remains unemployed, the effect is picked up by the previous month's dummy which represents an E to U transition. Analogously we drop out of our sample in every regression we run, households whose history doesn't feature any transition from employment to unemployment such as $\{U U, U U, U U\}$ (all unemployment spells) or $\{U U, U U, U E\}$ and so on. In the Tables we represent the histories that are dropped by underscores.

In Table 14 we show in column 2 how dropping couples with transitions from unemployment to employment affects our estimates. The coefficients $\alpha_{\tau}$ are now higher (except for two months ahead). The contemporaneous AWE is 0.0839 instead of 0.0784 . This is to be anticipated since those families that are not so lucky so as to receive a job offer (for all couples the wife is out of the LF at the beginning of each month) the fall in income and wealth is greater and therefore the spell variable in our regression should pick up a stronger AWE. The last three columns of Table 14 illustrate the estimates for the three separate samples. In column 3 we run the model considering as unemployed only individuals that lost their jobs (quits and layoffs were dropped). In column 4 we concentrate on quits and in 5 we look at families of temporarily laid off workers. As discussed in the text job losses and quits lead to a considerably larger response of participation of the female spouse. Finally, Table 15 repeats the same exercise for the search intensity variable.

\subsection{Competitive Equilibrium}

The equilibrium consists of a set of value functions $V^{i j}, i, j \in\{e, n\}$ and $V^{R}$, and a set of decision rules for consumption, asset holdings $\left(a_{i j}^{\prime}(a, \epsilon, \lambda, \Gamma)\right.$ for non retired households and 
Table 15: Dynamic Added Worker Effect: Search Intensity

\begin{tabular}{lccccc}
\hline & 1 & 2 & 3 & 4 & 5 \\
\hline \multirow{2}{*}{$\alpha_{-2}$} & $\mathrm{EU}_{m}$ & $\mathrm{EU}_{m}$ & Loss $_{m}$ & Quit & Layoff $_{m}$ \\
& $0.0994^{* * *}$ & $.0887^{* * *}$ & $0.0867^{* * *}$ & $0.0894^{* * *}$ & $.0 .0975^{* * *}$ \\
$\alpha_{-1}$ & $(0.01799)$ & $(0.0186)$ & $(0.0183)$ & $(0.0184)$ & $(0.0181)$ \\
& $0.1119^{* * *}$ & $0.1334^{* * *}$ & $0.1102^{* * *}$ & $0.1124^{* * *}$ & $0.1138^{* * *}$ \\
$\alpha_{-0}$ & $(0.01272)$ & $(0.0151)$ & $(0.0127)$ & $(0.0127)$ & $(0.0127)$ \\
& $0.2590^{* * *}$ & $.2955^{* * *}$ & $0.3936^{* * *}$ & $0.3877^{* *}$ & $0.1097^{* *}$ \\
$\alpha_{+1}$ & $(0.01001)$ & $(0.0132)$ & $(0.0149)$ & $(0.03660)$ & $(0.0148)$ \\
& $.2264^{* * *}$ & $.3668^{* * *}$ & $0.3284^{* * *}$ & $0.3104^{* * *}$ & $0.0864^{* * *}$ \\
$\alpha_{+2}$ & $(0.01233)$ & $(0.0199)$ & $(0.0186)$ & $(0469)$ & $(0.0194)$ \\
& $0.2920^{* * *}$ & $.5510^{*}$ & $0.3020^{* * *}$ & $0.1885^{* * *}$ & $0.1620^{* * *}$ \\
$\mathrm{R}^{2}$ & $(0.01689)$ & $(0.0299)$ & $(0.0194)$ & $(0.0237)$ & $(0.0214)$ \\
Observations & 0.0184 & 0.0181 & 0.0183 & 0.0162 & 0.0160 \\
\hline
\end{tabular}

This table shows the percentage point increase in the probability that a wife joins the labor force if her husband has made (will make) a transition from employment to unemployment two months ago, one month ago, this month, next month, or the month thereafter. [***] Significant at or below 1 percent. [**] Significant at or below 5 percent. [*] Significant at or below 10 percent.

$a_{R}^{\prime}(a, \epsilon, \lambda, \Gamma)$ for retired households), search intensity $\left(s_{k}^{i j}(a, \epsilon, \lambda, \Gamma) \in\{\underline{s}, \bar{s}\}\right)$, and labor supply $\left(h_{k}^{i j}(a, \epsilon, \lambda, \Gamma) \in\{0, \bar{h}\}\right.$ for $\left.k \in\{1,2\}\right)$. It also consists of a collection of quantities $\left\{K_{t}, L_{t}\right\}$ and prices $\left\{w_{t}, R_{t}\right\}$ and a law of motion of the distribution $\Gamma_{t+1}=T\left(\Gamma_{t}, \lambda_{t}\right)$ such that:

- Given prices households solve their maximization program in and optimal policies derive.

- The final goods firm maximizes its profits:

$$
w_{t}=K_{t}^{\alpha} \lambda_{t}^{1-\alpha} L_{t}^{-\alpha} \text { And } r_{t}=K_{t}^{-\alpha} \lambda_{t}{ }^{1-\alpha} L_{t}^{1-\alpha}
$$

- Goods and factor markets clear:

\section{Resource Constraint}

$$
\begin{gathered}
Y_{t}+(1-\delta) K_{t}=\frac{\phi_{2}}{\phi_{1}+\phi_{2}} \sum_{i, j} \int\left(a_{i j}^{\prime}\left(a, \epsilon, \Gamma_{t}, \lambda_{t}\right)+c_{i j}\left(a, \epsilon, \Gamma_{t}, \lambda_{t}\right)\right) d \Gamma_{t}^{i j} \\
+\left(1-\frac{\phi_{2}}{\phi_{1}+\phi_{2}}\right) \int\left(a_{R}^{\prime}\left(a, \epsilon, \Gamma_{t}, \lambda_{t}\right)+c_{R}\left(a, \epsilon, \Gamma_{t}, \lambda_{t}\right)\right) d \Gamma_{t}^{R}
\end{gathered}
$$

where $\Gamma_{t}^{i j}$ and $\Gamma_{t}^{R}$ denotes the conditional cdfs for households in states $i, j \in\{e, n\}$ and $R$ respectively.

\section{Labor Market}




$$
\begin{aligned}
& L_{t}=\int \epsilon_{1} h_{1}^{e n}\left(a, \epsilon, \lambda_{t}, \Gamma_{t}\right) \mathcal{I}\left(h_{1}^{e n}\left(a, \epsilon, \lambda_{t}, \Gamma_{t}\right)=\bar{h}\right) d \Gamma_{t}^{e n} \\
& +\int \epsilon_{2} h_{2}^{n e}\left(a, \epsilon, \lambda_{t}, \Gamma_{t}\right) \mathcal{I}\left(h_{2}^{n e}\left(a, \epsilon, \lambda_{t}, \Gamma_{t}\right)=\bar{h}\right) d \Gamma_{t}^{n e} \\
& +\sum_{i} \int \epsilon_{i} h_{i}^{e e}\left(a, \epsilon, \lambda_{t}, \Gamma_{t}\right) \mathcal{I}\left(h_{i}^{e e}\left(a, \epsilon, \lambda_{t}, \Gamma_{t}\right)=\bar{h}\right) d \Gamma_{t}^{e e}
\end{aligned}
$$

\section{Savings Market}

$$
K_{t}=\int a_{t} d \Gamma_{t}
$$

- Individual behavior is consistent with the aggregate behavior. In particular the law of motion of the measure $\Gamma$ can be represented as follows:

$$
\begin{aligned}
\Gamma_{t+1}^{e e}(\mathcal{A}, \mathcal{E})= & \left(1-\phi_{1}\right)\left(\int_{a_{e e}^{\prime} \in \mathcal{A}, \epsilon^{\prime} \in \mathcal{E}} \mathcal{I}\left(h_{1}^{e e}=\bar{h} \cap h_{2}^{e e}=\bar{h}\right)(1-\chi(\lambda))^{2} d \pi_{\epsilon^{\prime} \mid \epsilon} d \Gamma_{t}^{e e}\right. \\
+ & \int_{a_{e n}^{\prime} \in \mathcal{A}, \epsilon^{\prime} \in \mathcal{E}} \mathcal{I}\left(h_{1}^{e e}=\bar{h} \cap h_{2}^{e e}=\bar{h}\right)(1-\chi(\lambda)) p\left(s_{2}^{e n}, \lambda_{t}\right) d \pi_{\epsilon^{\prime} \mid \epsilon} d \Gamma_{t}^{e n} \\
+ & \int_{a_{n}^{\prime} \in \mathcal{A}, \epsilon^{\prime} \in \mathcal{E}} \mathcal{I}\left(h_{1}^{e e}=\bar{h} \cap h_{2}^{e e}=\bar{h}\right)\left(1-\chi\left(\lambda_{t}\right)\right) p\left(s_{1}^{n e}, \lambda_{t}\right) d \pi_{\epsilon^{\prime} \mid \epsilon} d \Gamma_{t}^{n e} \\
+ & \left.\int_{a_{n n}^{\prime} \in \mathcal{A}, \epsilon^{\prime} \in \mathcal{E}} \mathcal{I}\left(h_{1}^{e e}=\bar{h} \cap h_{2}^{e e}=\bar{h}\right) p\left(s_{1}^{n n}, \lambda_{t}\right) p\left(s_{2}^{n n}, \lambda_{t}\right) d \pi_{\epsilon^{\prime} \mid \epsilon} d \Gamma_{t}^{n n}\right) \\
\Gamma_{t+1}^{e n}(\mathcal{A}, \mathcal{E})= & \left(1-\phi_{1}\right) \int_{a_{e e}^{\prime} \in \mathcal{A}, \epsilon^{\prime} \in \mathcal{E}} \mathcal{I}\left(h_{1}^{e e}=\bar{h} \cap h_{2}^{e e}=0\right)(1-\chi(\lambda))^{2} d \pi_{\epsilon^{\prime} \mid \epsilon} d \Gamma_{t}^{e e} \\
+ & \int_{a_{e n}^{\prime} \in \mathcal{A}, \epsilon^{\prime} \in \mathcal{E}} \mathcal{I}\left(h_{1}^{e e}=\bar{h} \cap h_{2}^{e e}=0\right)\left(1-\chi\left(\lambda_{t}\right)\right) p\left(s_{2}^{e n}, \lambda_{t}\right)+ \\
& \mathcal{I}\left(h_{1}^{e n}=\bar{h}\right)\left(1-\chi\left(\lambda_{t}\right)\right)\left(1-p\left(s_{2}^{e n}, \lambda_{t}\right)\right) d \pi_{\epsilon^{\prime} \mid \epsilon} d \Gamma_{t}^{e n} \\
+ & \int_{a_{n e}^{\prime} \in \mathcal{A}, \epsilon^{\prime} \in \mathcal{E}} \mathcal{I}\left(h_{1}^{e e}=\bar{h} \cap h_{2}^{e e}=0\right)\left(1-\chi\left(\lambda_{t}\right)\right) p\left(s_{1}^{n e}, \lambda_{t}\right) \\
+ & \mathcal{I}\left(h_{1}^{e n}=\bar{h}=0\right)\left(\chi\left(\lambda_{t}\right)\right) p\left(s_{1}^{n e}, \lambda_{t}\right) d \pi_{\epsilon^{\prime} \mid \epsilon} d \Gamma_{t}^{n e} \\
+ & \int_{a_{n n}^{\prime} \in \mathcal{A}, \epsilon^{\prime} \in \mathcal{E}} \mathcal{I}\left(h_{1}^{e e}=\bar{h} \cap h_{2}^{e e}=0\right) p\left(s_{1}^{n n}, \lambda_{t}\right) p\left(s_{2}^{n, n}, \lambda_{t}\right) \\
+ & \left.\left.\mathcal{I}\left(h_{1}^{e n}=\bar{h}\right) p\left(s_{1}^{n n}, \lambda_{t}\right)\left(1-p\left(s_{2}^{n n}, \lambda_{t}\right)\right)\right) d \pi_{\epsilon^{\prime} \mid \epsilon} d \Gamma_{t}^{n n}\right)
\end{aligned}
$$

The law of motion of $\Gamma_{t}^{n e}$ is similarly defined. 


$$
\begin{aligned}
& \Gamma_{t+1}^{n n}(\mathcal{A}, \mathcal{E})=(1\left.-\phi_{1}\right) \int_{a_{e e}^{\prime} \in \mathcal{A}, \epsilon^{\prime} \in \mathcal{E}} \mathcal{I}\left(h_{1}^{e e}=0 \cap h_{2}^{e e}=0\right)\left(1-\chi\left(\lambda_{t}\right)\right)^{2}+\chi\left(\lambda_{t}\right)^{2} d \pi_{\epsilon^{\prime} \mid \epsilon} d \Gamma_{t}^{e e} \\
&+ \int_{a_{e n}^{\prime} \in \mathcal{A}, \epsilon^{\prime} \in \mathcal{E}} \mathcal{I}\left(h_{1}^{e e}=\bar{h} \cap h_{2}^{e e}=0\right)\left(1-\chi\left(\lambda_{t}\right)\right) p\left(s_{2}^{e n}, \lambda_{t}\right) \\
&+\mathcal{I}\left(h_{1}^{e n}=\bar{h}\right)\left(1-\chi\left(\lambda_{t}\right)\right)\left(1-p\left(s_{2}^{e n}, \lambda_{t}\right)\right) d \pi_{\epsilon^{\prime} \mid \epsilon} d \Gamma_{t}^{e n} \\
&+ \int_{a_{n e}^{\prime} \in \mathcal{A}, \epsilon^{\prime} \in \mathcal{E}} \mathcal{I}\left(h_{1}^{e e}=\bar{h} \cap h_{2}^{e e}=0\right)\left(1-\chi\left(\lambda_{t}\right)\right) p\left(s_{1}^{n e}, \lambda_{t}\right) \\
&+\mathcal{I}\left(h_{1}^{e n}=\bar{h}=0\right)\left(\chi\left(\lambda_{t}\right)\right) p\left(s_{1}^{n e}, \lambda_{t}\right) d \pi_{\epsilon^{\prime} \mid \epsilon} d \Gamma_{t}^{n e} \\
&+ \int_{a_{n n}^{\prime} \in \mathcal{A}, \epsilon^{\prime} \in \mathcal{E}} \mathcal{I}\left(h_{1}^{e e}=\bar{h} \cap h_{2}^{e e}=0\right) p\left(s_{1}^{n n}, \lambda_{t}\right) p\left(s_{2}^{n n}, \lambda_{t}\right) \\
&\left.+\mathcal{I}\left(h_{1}^{e n}=\bar{h}\right) p\left(s_{1}^{n n}, \lambda_{t}\right)\left(1-p\left(s_{2}^{n n}, \lambda_{t}\right)\right)\right) d \pi_{\epsilon^{\prime} \mid \epsilon} d \Gamma_{t}^{n n} \\
& \phi_{2} \int_{a_{R}^{\prime} \in \mathcal{A}, \epsilon^{\prime} \in \mathcal{E}} d \pi_{\epsilon^{\prime} \mid \epsilon} d \Gamma_{t}^{R} \\
& \Gamma_{t+1}^{R}(\mathcal{A}, \mathcal{E})=\phi_{1}\left(\int_{a_{e e}^{\prime} \in \mathcal{A}, \epsilon^{\prime} \in \mathcal{E}} d \pi_{\epsilon^{\prime} \mid \epsilon} d \Gamma_{t}^{e e}+\int_{a_{e n}^{\prime} \in \mathcal{A}, \epsilon^{\prime} \in \mathcal{E}} d \pi_{\epsilon^{\prime} \mid \epsilon} d \Gamma_{t}^{e n}\right. \\
&\left.+\int_{a_{n e}^{\prime} \in \mathcal{A}, \epsilon^{\prime} \in \mathcal{E}} d \pi_{\epsilon^{\prime} \mid \epsilon} d \Gamma_{t}^{n e}+\int_{a_{n n}^{\prime} \in \mathcal{A}, \epsilon^{\prime} \in \mathcal{E}} d \pi_{\epsilon^{\prime} \mid \epsilon} d \Gamma_{t}^{n n}\right) \\
&\left(1-\phi_{2}\right) \int_{a_{R}^{\prime} \in \mathcal{A}, \epsilon^{\prime} \in \mathcal{E}} d \pi_{\epsilon^{\prime} \mid \epsilon} d \Gamma_{t}^{R}
\end{aligned}
$$

Where $\mathcal{A}$ and $\mathcal{E}$ are subsets of the relevant state space. The object $\mathcal{I}\left(h_{k}^{i j}=\bar{h}\right)$ takes the value one if the agent's desired labor is $\bar{h}$ and takes the value 0 otherwise.

\subsection{Computational strategy for steady-state equilibrium}

In steady state, factor prices are constant and the distribution of agents over the relevant state space $\Gamma$ is time invariant. The calibration consists of two nested loops. The outer loop is the market clearing loop. We guess a value for the discount factor $\beta$ and we fix the interest rate $R(\bar{\lambda})-1$ to be equal to $0.41 \%$ (a quarterly analogue of $1.24 \%$ ). Using these we solve the agent's program and we obtain the steady state distribution $\Gamma$ ). The steady sate distribution yields an aggregate savings supply. If the implied marginal product of capital net of depreciation is equal to the calibrated value for the interest rate, we found the equilibrium. If not, we update our guess for the discount factor $\beta$. We use a simple bisection algorithm to minimize the number of iterations.

The inner loop is the value function iteration. Details are as follows:

1. We choose an unevenly spaced grid for asset holdings $(a)$ (with more nodes near the borrowing constraint) and a grid for individual productivities $\epsilon$. We experiment with different number of nodes for the asset grid, usually between $N_{a}=101$ and $N_{a}=161$.

2. Given the interest rate, the discount factor and the wage rate $w(\bar{\lambda})$ (the latter follows from the production technology), we solve the family's optimal program via value function iteration. We start with an initial guess for the lifetime utilities, we approximate numerically the optimal policies (for savings, search and labor supply) 
and we update the guess. Values that fall outside the grid are interpolated with cubic splines. Once the value functions have converged we recover the optimal policy functions of the form $a^{\prime}(a, \epsilon)$ (savings), $s(a, \epsilon)$ (search) and $h(a, \epsilon)$ (employment).

3. The final step is to obtain the invariant measure $\Gamma$ over the relevant state space (asset productivities and employment status).

(a) We first approximate the optimal policy rules on a finer grid which $N_{a_{B I G}}=2000$ nodes and we initialize our measure $\Gamma_{0}$.

(b) We update it and obtain a new measure $\Gamma_{1}$

(c) The invariant measure is found when the maximum difference between $\Gamma_{0}$ and $\Gamma_{1}$ is smaller than a pre-specified tolerance level.

(d) By using the invariant measure, we compute aggregate labor supply and asset supply. This implies a new marginal product of capital which we then compare to our initial guess.

\subsection{Computational strategy for equilibrium with aggregate fluc- tuations}

Aggregate shocks imply that factor prices are time varying. When solving their optimization program, agents have to predict future factor prices. Therefore, they have to predict all the individual policy decisions in all possible future states. This requires agents to keep track of every other agent. Thus, in order to approximate the equilibrium in the presence of aggregate shocks, one has to keep track of the measure of all groups of agents over time. Since $\Gamma$ is an infinite dimensional object, it is impossible to do this directly. We therefore follow Krusell and Smith (1998) and assume that agents are boundedly rational and use only the mean of wealth and aggregate productivity to forecast future capital $K$ and factor prices $w$ and $R$.

Compared to the steady-state algorithm, we now have two additional state variables that we must add to the list of the existing state variables in the inner loop: aggregate productivity $\lambda$ and aggregate capital $K$. As the outer loop, we iterate on the forecasting equations for aggregate capital and factor prices. ${ }^{34}$ The details are as follows:

1. We approximate the aggregate productivity process with 4 nodes and standard techniques to obtain the values and transition probabilities. We choose a capital grid around the steady-state level of capital $K^{s} s$, in particular, we put $N_{k}=25$ equally spaced nodes to form a grid with the range $\left[0.8 * K^{s s} ; 1.2 K^{s s}\right]$.

2. As already mentioned, we choose the means of aggregate capital and aggregate productivity to be the explanatory variables in the forecasting equations. We use a log-linear form

$$
\begin{aligned}
\ln K_{t+1} & =\kappa_{0}^{0}+\kappa_{1}^{0} \ln K_{t}+\kappa_{2}^{0} \ln \lambda_{t} \\
\ln w_{t} & =\omega_{0}^{0}+\omega_{1}^{0} \ln K_{t}+\omega_{2}^{0} \ln \lambda_{t} \\
\ln R_{t} & =\varrho_{0}^{0}+\varrho_{1}^{0} \ln K_{t}+\varrho_{2}^{0} \ln \lambda_{t}
\end{aligned}
$$

\footnotetext{
${ }^{34}$ In the steady state algorithm, there were three loops. Since we use the steady state values for the endogenous parameters, we do not have an estimation loop here.
} 
3. We initialize the coefficients so that $K_{t+1}, w, R$ are equal to their steady state values.

4. Given equations 8 to 10 , we solve the value function problems as before, only now the state vector is four-dimensional. Values that are not on the asset grid are interpolated using cubic splines. Values that are not on the aggregate capital grid are interpolated linearly.

5. Instead of simulating the economy with a large finite number of agents, we use the procedure of Young (2010) and simulate a continuum of agents. This procedure has the advantage of avoiding cross-sectional sampling variation. We simulate the economy for 10,000 periods and discard the first 2,000. In each period, we get an observation for $K, w$ and $R$. We use the simulated data to run OLS regressions on equations 8-10 which yield new coefficient estimates for the $\kappa^{1} \mathrm{~s}$, the $\omega^{1} \mathrm{~s}$, and the $\varrho^{1} \mathrm{~s}$. If these coefficients are close to the previous ones, we stop; otherwise, we update equations 8-10 with the new coefficients and solve the problem again.

The convergent solutions for the forecasting equations of our models are

Table 16: Convergent Solutions

\begin{tabular}{lcccc}
\hline Equation & Constant & $\ln \left(K_{t}\right)$ & $\ln \left(\lambda_{t}\right)$ & $R^{2}$ \\
\hline $\ln \left(K_{t+1}\right)$ & 0.04679 & 0.98973 & 0.006243 & 0.99996 \\
$\ln \left(w_{t}\right)$ & -0.12052 & 0.29193 & 0.027955 & 0.99627 \\
$\ln \left(R_{t}\right)$ & 0.04004 & -0.00770 & 0.033506 & 0.99108 \\
\hline
\end{tabular}

This table shows the coefficients of the forecasting rules used by the agents under aggregate uncertainty. 